\title{
Bio-based epoxy thermosets with rosin derived imidoamine curing agents and their structure-property relationships
}

\author{
T. Thakur, S. Jaswal, S. Parihar, B.Gaur*, A. S. Singha \\ Department of Chemistry, National Institute of Technology Hamirpur, 177005 Hamirpur, India
}

Received 11 July 2019; accepted in revised form 14 September 2019

\begin{abstract}
Multifunctional bio-based epoxy resin (PEMPAE) was synthesized by reacting Diels-Alder adduct of gum rosin and maleic anhydride (MPA) with pentaerythritol to get the esterified product (PEMPA) which was further epoxidized using epichlorohydrin and potassium hydroxide. This paper includes the synthesis of bio-based imidoamine curing agent (IAEDK) by reacting diamino diphenyl ether (DDE) with dimaleopimaryl ketone (DMPK), a dehydrodecarboxylated derivative of MPA. The synthesized products were characterized by Fourier transform infrared Spectroscopy (FTIR), proton and ${ }^{13} \mathrm{C}$ nuclear magnetic resonance spectroscopy $\left({ }^{1} \mathrm{H}-\mathrm{NMR}\right.$ and $\left.{ }^{13} \mathrm{C}-\mathrm{NMR}\right)$. Curing dynamics of rosin-based epoxy cured with rosinbased imidoamine crosslinker were evaluated using differential scanning calorimetry (DSC) and were compared with resin cured with synthesized DMPK and commercial DDE curing agents. The mechanical properties and thermal stability of the cured epoxy samples were evaluated using a universal testing machine (UTM) and thermogravimetric analyzer (TGA), respectively. The chemical resistance of the samples was determined in terms of \% weight loss when immersed in $\mathrm{NaOH}, \mathrm{HCl}$ and $\mathrm{NaCl}$ solutions. The morphological changes were also evaluated via scanning electron microscopy (SEM). Results revealed that rosin-based epoxy cured with imidoamine curing agent gave preeminent properties over the commercial one. The studies suggested that curing properties were greatly affected by the molecular topology and kind of curing agent used.
\end{abstract}

Keywords: thermosetting resins, rosin, bio-based epoxy, imidoamine curing agent, thermal properties

\section{Introduction}

Dwindling petroleum resources and growing environmental concerns have led the modern-day polymer technologist to explore the utilization of bio-based scaffolding materials for polymers as an alternative. Rosin, obtained from pine trees, is an abundant biobased material having the potential of chemical modification. It consists of a mixture of pimaric (30$40 \%)$ and abietic type (20-30\%) acids along with a smaller fraction of neutral components (10-20\%). The inherent acid groups and double bonds in their moiety facilitate it to be transformed into a variety of derivatives such as salts, hydrogenated and decarboxylated rosins, esters, and anhydride adducts [1]. The chemically modified rosin is frequently used in manufacturing paints, varnishes, adhesive tackifiers, paper sizing agents, solders and fluxes, electronic insulating materials, printing inks, soaps, etc. [2]. Much focus these days is to exploit bio-based raw material for the synthesis of new materials with specific chemical structures and enhanced properties to replace the petroleum incumbents.

Epoxy resins are the most commonly employed thermosetting polymers, having high processing capability and a wide range of industrial applications such as protective coatings, insulating material for electrical and electronic components, adhesives, high-performance composites, encapsulants for semiconductors, concrete flooring, etc. [3]. The selection of epoxies for several fields of its application is based on their superior adhesion, excellent mechanical strength, permeability, high stiffness, outstanding 
chemical resistance properties [4]. Epoxy resins can be transformed into high-performance thermosetting resins via curing process wherein epoxy monomers are permanently crosslinked with suitable curing agents [5]. Amine based curing agents are of major importance among widely used and all known curing agents $[6,7]$. In particular, aromatic amines as curing agents offer advantages of excellent chemical resistance, high-temperature stability, and good mechanical strength. Also, imide compounds end-capped with amines that contain aromatic groups have been used to impart flame resistance properties to the thermosetting resins $[8,9]$.

With the exhaustion of inherently finite fossil resources, the need for considering renewable resources in coating technologies is, therefore, obvious [10 13]. In recent times, few articles have reported the use of gum rosin as a scaffold material for synthesizing epoxy resins, providing an attractive alternative to prepare epoxy resins devoid of toxic and harmful Bisphenol-A which is a commercially used epoxy prepolymer [14]. Maleopimaric acid, a Diels-Alder adduct of rosin with maleic anhydride, has been used as a precursor for synthesizing bifunctional, trifunctional and multifunctional epoxy resins and curing agents that show great potential to replace some of the current petroleum-based products [15-18]. Several reports used ketone derivatives of rosin and condensed rosin acid-formaldehyde resins for preparing epoxy resins that show higher $T_{\mathrm{g}}$ value, enhanced thermal stability, and mechanical properties as compared to DGEBA [19-24]. Liu and coworkers [2529] reported novel rosin-based imide-diacids and flexible anhydride type curing agents. A series of cured epoxy thermosets were prepared, and curing behavior was compared with commercial curing agents. They investigated thermal stability, tensile and mechanical properties of the rosin-based imide-diacids cured epoxy resins. The results demonstrated enhanced thermal performance, higher $T_{\mathrm{g}}$ values and superior mechanical properties of thermosetting resins attained by introducing rosin backbone in epoxy resins and curing agents. Moreover, modification of other various structurally versatile epoxy resins and curing agents with aromatic imides have been reported to show good fire-retardant properties [30, 31].

The present work focuses on the use of rigid hydrogenated phenanthrene moiety of gum rosin to synthesize both multifunctional bio-based epoxy resin as well as the curing agent. In this study, rosin derived hyperbranched pentaerythritol based epoxy resin and rosin-based imidoamine curing agent was synthesized. The rigid rosin moiety is introduced in order to achieve higher glass transition, good thermal stability, and high mechanical strength of the cured epoxy thermosets. However, the fused rosin ketone structure used in the curing agent construction imparts brittleness to the resulting thermoset; hence, to overcome this issue, flexible diaminodiphenyl ether is incorporated into the dirosin-ketone structure via imide linkages. Furthermore, soft linear aliphatic ether segments present in pentaerythritol epoxy work as a flexible spacer between the huge imido-amine molecules in the crosslinked network structure. The pentaerythritol based epoxy resin was cured with rosin-based imidoamine, dimaleopimaryl ketone, and diaminodiphenyl ether curing agents. Their curing kinetics were studied and for comparison, trimethylol based epoxy resin (synthesized in our previous study [17]) was also cured with above mentioned curing agents. Thermal, mechanical and chemical resistance properties were also investigated. This study provides a novel method to develop fully bio-based high-performance thermosetting resin and further, the results demonstrate the feasibility of using it as a substitute for some existing petroleum-based resins and curing agents.

\section{Materials and methods}

\subsection{Materials}

Epoxy resin was synthesized using Gum rosin (WW grade, Midhills Rosin \& Turpenes, India), maleic anhydride (99\% pure, Lobachemie Pvt. Ltd., India), pentaerythritol (98\% pure, Lobachemie Pvt. Ltd., India), $p$-toluenesulfonic acid (98\% pure, Lobachemie Pvt. Ltd., India), epichlorohydrin L. R. grade (99\% pure, Lobachemie Pvt. Ltd., India) and potassium hydroxide (85\% pure, Avra Synthesis Pvt. Ltd, India). For synthesizing curing agents Diaminodiphenyl ether (98\%, Alfa Aesar, UK), anhydrous sodium acetate (99\% pure, CDH Pvt. Ltd, India), 2,4-Dichlorotoluene (98\% pure, TCI Chemicals Pvt. Ltd, Japan) and propionic anhydride (98\% pure, Sisco Research Laboratories Pvt. Ltd., India) were used. Solvents: acetic acid, xylene, toluene, dimethylformamide, ethyl acetate, petroleum ether, diethyl ether (Himedia Laboratories Pvt. Ltd., India) of reagent grade were used as received. 


\subsection{Synthesis of bio-based epoxy resin 2.2.1. Synthesis of MPA}

In a three-necked $100 \mathrm{ml}$ round bottom flask equipped with a mechanical stirrer, thermometer, and a reflux condenser, gum rosin $(10 \mathrm{~g})$ was added and heated to the melting range of $175-180^{\circ} \mathrm{C}$ under $\mathrm{N}_{2}$ atmosphere. The temperature was maintained for the next 3 hours to complete the isomerization of abietic acid to levopimaric acid and then the reaction mixture was cooled to $120^{\circ} \mathrm{C}$. After that maleic anhydride $(2.35 \mathrm{~g})$, acetic acid $(30 \mathrm{ml})$ and $p$-toluenesulfonic $\operatorname{acid}(0.46 \mathrm{~g})$ were added and refluxed for next 12 hours. Upon cooling, a yellow solid crude product was obtained which was further recrystallized with acetic acid to give white crystals of pure MPA. Yield $92 \%$.

\subsubsection{Synthesis of esterified adduct of MPA with pentaerythritol (PEMPA)}

To a $100 \mathrm{ml}$ three-necked round bottom flask fitted with mechanical stirrer, Dean and stark apparatus and thermometer, MPA (10 g), Pentaerythritol (6.4 g), xylene $(10 \mathrm{ml})$ and $p$-TSA ( $1 \mathrm{wt} \%$ of total weight of reactants) was charged. The reaction mixture was refluxed until 6 moles of water were collected. A light yellow solid product was obtained and washed with hot water to remove unreacted pentaerythritol. Yield 91\%.

\subsubsection{Synthesis of epoxy resin (PEMPAE)}

$30 \mathrm{~g}$ PEMPA and $220 \mathrm{ml}$ DMSO were mixed at $24^{\circ} \mathrm{C}$ in a reaction kettle equipped with a mechanical stirrer, water bath, and reflux condenser. After PEMPA was dissolved, $116 \mathrm{~g}$ of $\mathrm{KOH}$ was added to the reaction mixture and the temperature was maintained to $15-20^{\circ} \mathrm{C}$ using ice in a water bath. To this mixture, $272 \mathrm{ml}$ of epichlorohydrin was added dropwise in 1.5 hours and continued stirring for the next 16 hours. The reaction product was then extracted with equal amounts of dichloromethane and water mixture. After separating the non-aqueous layer, excess of Dichloromethane was distilled off under reduced pressure and the light yellow colored epoxy resin was obtained.

\subsection{Synthesis of bio-based imidoamine curing agent}

\subsubsection{Synthesis of ketone derivative of MPA} (DMPK)

Dimaleopimaryl ketone (DMPK) was synthesized by acid-catalyzed dehydrodecarboxylation reaction of MPA. A mixture of $101 \mathrm{~g}$ of MPA and $50 \mathrm{ml}$ of toluene was charged to a reaction vessel fitted with a mechanical stirrer, Dean and Stark apparatus, thermometer, and an $\mathrm{N}_{2}$ inlet. The reaction mixture was heated to $112^{\circ} \mathrm{C}$ and refluxed for 30 mins. $1 \mathrm{~g}$ of $p$-TSA was added and refluxed for the next 15 mins. After collection of about $0.5 \mathrm{ml}$ of water in deanstark, the reaction temperature was slowly raised to $200^{\circ} \mathrm{C}$ for the next 2.5 hours with the gradual removal of toluene from the reaction mixture. At this instant, the removal of byproducts $\left(\mathrm{CO}_{2}\right.$ and water) was observed. The reaction was completed during the next 30 mins. A brownish colored solid crude product was obtained which was purified by dissolving in diethyl ether and then after filtration, precipitation was done with petroleum ether. Yield 52\%.

\subsubsection{Synthesis of imidoamine-ether- dimerketone (IAEDK) curing agent}

Imidoamine curing agent was synthesized by reacting one mole of DMPK with excess $(2.5 \mathrm{~mol})$ of diaminodiphenylether (DDE). Firstly, a solution of $10 \mathrm{~g}$ of DDE in $50 \mathrm{ml}$ of 2,4-dichlorotoluene was added to a $100 \mathrm{ml}$ three-neck round bottom flask fitted with a stirrer, Liebig condenser, and thermometer. The solution was heated to boiling and then a hot solution of $15.4 \mathrm{~g}$ of DMPK in $150 \mathrm{ml}$ of 2,4-dichlorotoluene was added dropwise in next 15 mins during constant boiling. The contents were refluxed for the next 5 hours. The solvent was then removed by the rotatory evaporator. Dark brown colored residual crude was obtained which was purified in ethyl acetate and dried. Yield 58\%.

\subsection{Curing procedure}

Epoxy resins PEMPAE and TMPAE were cured with imidoamine curing agent (IAEDK), DMPK and DDE. Six different samples were prepared by mixing the epoxy resin and curing agent in a 1:1 equivalent ratio in a beaker and dissolved in a small amount of acetone in order to achieve a homogenous mixture. The mixture was stirred for $30 \mathrm{mins}$ at room temperature and then the solvent was removed in a vacuum oven at $50{ }^{\circ} \mathrm{C}$ for 3 hours. After that, the mixture was transferred into a mold with dimensions $100 \times 50 \times 5 \mathrm{~mm}$. The curing was done under constant pressure in a compression molding machine at $90^{\circ} \mathrm{C}$ for $1 \mathrm{~h}$, $120^{\circ} \mathrm{C}$ for $2 \mathrm{~h}, 150^{\circ} \mathrm{C}$ for $2 \mathrm{~h}$. The samples were cooled to room temperature and removed carefully from the mold. The resulting sheet of the cured sample 
was cut into rectangular strips of $100 \times 10 \times 5 \mathrm{~mm}$ size for testing the mechanical properties.

\subsection{Characterizations}

The structural characterization of all the synthesized compounds was done using FTIR, ${ }^{1} \mathrm{H}-\mathrm{NMR}$, and ${ }^{13} \mathrm{C}$-NMR spectroscopic techniques. FTIR spectra were recorded in $\mathrm{KBr}$ pellets using Perkin Elmer L1600312 FTIR spectrometer in range 4000 $500 \mathrm{~cm}^{-1} .{ }^{1} \mathrm{H}-\mathrm{NMR}$ and ${ }^{13} \mathrm{C}-\mathrm{NMR}$ spectra were measured on Jeol India JNM ECX -500 spectrometer in $\mathrm{CDCl}_{3}$ solvent. The molecular weight of bio-based epoxy resin and imidoamine curing agent was determined using Perkin Elmer turbo matrix-40 Gel Permeation Chromatograph. Tetrahydrofuran (THF) was used as a mobile and stationary phase in GPC. The curing behavior of epoxy resins with synthesized and commercial curing agents was studied by DSC. For this, SDT Q600 V20.9 Build 20 Differential Scanning Calorimeter was used and the scans were recorded by taking $2 \mathrm{mg}$ (approx.) of the sample into alumina crucible from 20 to $250^{\circ} \mathrm{C}$ dynamically with a heating rate of $10^{\circ} \mathrm{C} / \mathrm{min}$. Thermogravimetric analysis experiments were conducted using EXSTAR TG/ DTA 6300 under nitrogen atmosphere at a constant heating rate of $10^{\circ} \mathrm{C} / \mathrm{min}$. The mechanical analysis of cured samples was carried out to study the tensile strength, compressive strength and flexural properties using Hounsefield-25KN universal testing machine at a strain rate of $2 \mathrm{~mm} / \mathrm{min}$.

The chemical resistance of the cured epoxy resins was also evaluated according to ASTM method as reported in a previous study [23] using mild steel specimens $(15 \times 10 \mathrm{~cm})$, one side of which is coated with coal tar epoxy primer and another side with an epoxy resin containing amine hardener having thickness $250 \pm 10 \mu \mathrm{m}$ via hand layup method and was cured. These specimens were then immersed in $1 \mathrm{M}$ $\mathrm{NaOH}, 1 \mathrm{M} \mathrm{HCl}$, and $1 \mathrm{M} \mathrm{NaCl}$ solutions for 90 days at room temperature. The chemical resistance was determined by analysis based on weight loss of the cured resin coated on steel specimens using Equation (1):

Weight loss $[\%]=\frac{W_{\mathrm{i}}-W_{\mathrm{f}}}{W_{\mathrm{i}}}$

where $W_{\mathrm{i}}$ is the weight of the dry sample before immersion and $W_{\mathrm{f}}$ is the weight of the dry sample after immersion. Morphological changes on the surface of the tested side of the specimen due to chemical exposure were observed using the JSM-6610 Scanning electron microscope.

\section{Results and discussion}

Gum rosin consists of $90 \%$ rosin acids (pimaric and abietic type) and 10\% neutral compounds. Rosin acids show chemical reactivity due to the presence of two main functionalities: conjugated double bonds and monocarboxylic acid groups. Out of eight closely related rosin acid isomers, only levopimaric acid possesses the homoannular double bonds for DielsAlder cycloaddition. However, the other rosin acids can be isomerized to levopimaric acid by heating at elevated temperatures which can further be modified with maleic anhydride to get Diels-Alder adduct (MPA). To introduce flexibility and hydroxyl functionality, this adduct was further reacted with pentaerythritol, an appropriate candidate due to its aliphatic hydrocarbon chain and four hydroxyl groups. The hydroxyl groups were epoxidized to synthesize multifunctional epoxy resin. Hence, a nonaglycidyl ester of pentaerythritol modified MPA based epoxy resin was prepared. In order to obtain a highperformance epoxy thermoset, a rosin-based crosslinker was also prepared. This amine type rosin crosslinker in conjunction with imide units was synthesized by firstly dehydrodecarboxylating MPA to get dimaleopimaryl ketone which was further reacted with diaminodiphenyl ether to form an imidoamine. Thus, epoxy resin and crosslinker were mixed together in the stoichiometric ratio to yield thermosetting resin with enhanced mechanical and thermal strength.

\subsection{Synthesis and characterization}

Figure 1 and 2 depicts the synthesis of pentaerythritol rosin epoxy resin (PEMPAE) and imidoamine (IAEDK) curing agent, respectively. The chemical structure of PEMPAE epoxy resin was confirmed by FTIR, ${ }^{1} \mathrm{H}-\mathrm{NMR}$, and ${ }^{13} \mathrm{C}-\mathrm{NMR}$ techniques. Figure $4 \mathrm{a}$ shows FTIR spectra for PEMPAE epoxy resin and its precursors MPA and PEMPA. The FTIR spectrum of MPA shows a broad absorption peak in range 3300$3600 \mathrm{~cm}^{-1}$ for the carboxylic $-\mathrm{OH}$ stretching, two stretching bands at 1828 and $1766 \mathrm{~cm}^{-1}$ for anhydride stretching and a peak at $1678 \mathrm{~cm}^{-1}$ for $\mathrm{C}=\mathrm{O}$ of carboxylic acid which confirms the Diels-Alder adduct formation. In the FTIR spectrum of PEMPA, peaks at 1700 and $1730 \mathrm{~cm}^{-1}$ due to the carbonyl of acid and ester appeared and the peaks due to anhydride 

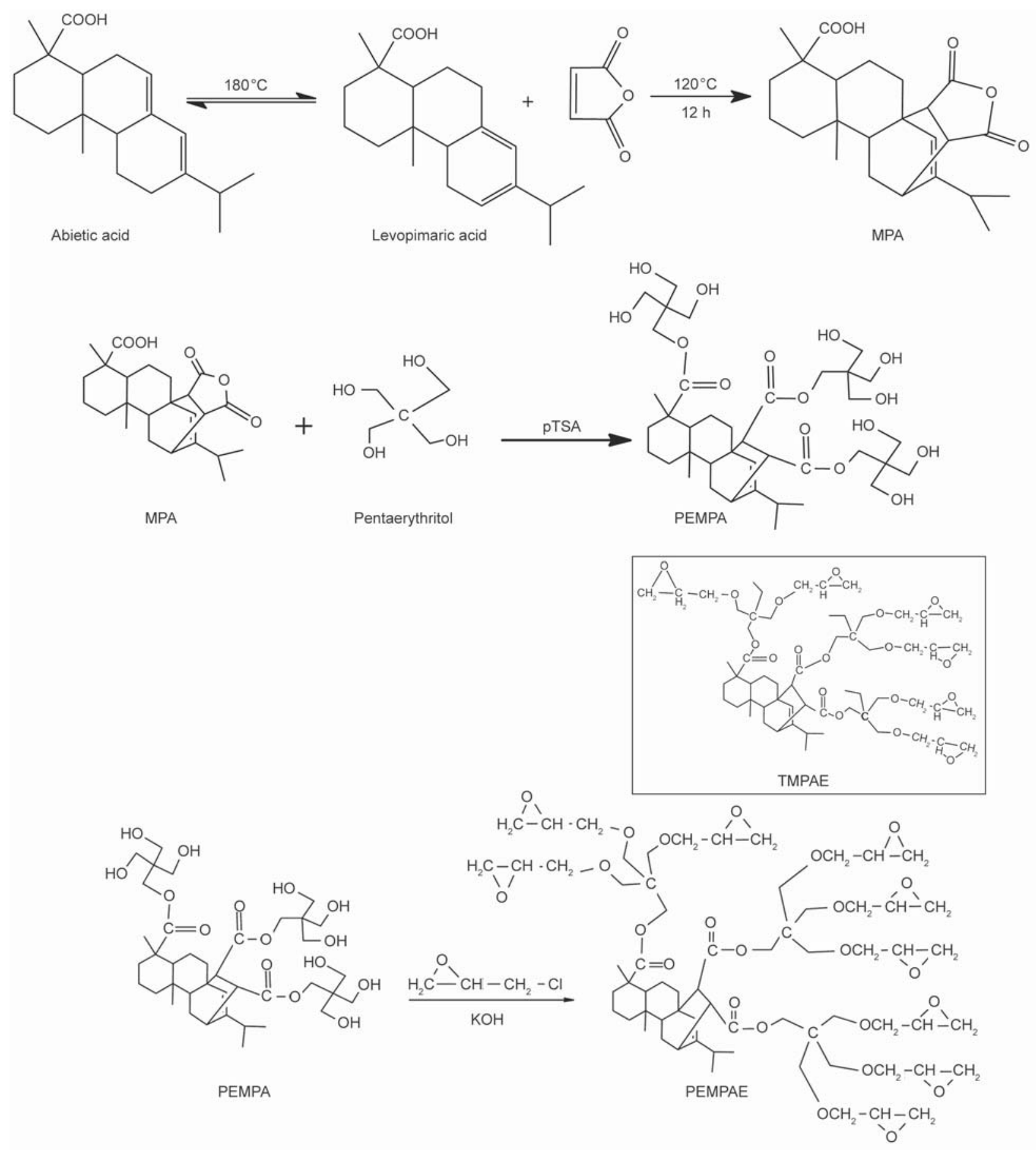

Figure 1. Synthetic route for PEMPAE epoxy resin.

disappeared which confirms the esterification of MPA with pentaerythritol. For epoxy resin PEMPA, three characteristic bands for $\mathrm{C}-\mathrm{O}$ stretching: symmetric at $1240 \mathrm{~cm}^{-1}$ and asymmetric at 887 and $821 \mathrm{~cm}^{-1}$ were observed. Figure 5 shows the ${ }^{1} \mathrm{H}-\mathrm{NMR}$ spectra of MPA (Figure 5a), PEMPA (Figure 5b) and PEMPAE (Figure 5c). For MPA, the signal at $5.5 \mathrm{ppm}$ is due to the proton (3) at unsaturated carbon, the signal at $11.6 \mathrm{ppm}$ is due to carboxylic acid proton (6) and other peaks were also identified. The ${ }^{1} \mathrm{H}-\mathrm{NMR}$ of PEMPA shows signal due to hydroxyl protons at 3.6-4.2 ppm confirming esterification of MPA with pentaerythritol. The peak at $5.5 \mathrm{ppm}$ is retained which shows that the MPA structure remains intact during the esterification reaction. The structure of epoxy resin PEMPAE was confirmed by ${ }^{1} \mathrm{H}-\mathrm{NMR}$ spectrum (Figure $5 \mathrm{c}$ ) as the peak assigned to hydroxyl protons was not observed in the range 3.6$402 \mathrm{ppm}$. The presence of signals at 2.6 and $2.8 \mathrm{ppm}$ was due to protons $\mathbf{4}$ and $\mathbf{5}$ of the oxirane ring, respectively. The peak observed at $3.1 \mathrm{ppm}$ is attributed to proton (1) and a multiplet at 3.3-3.8 ppm is 


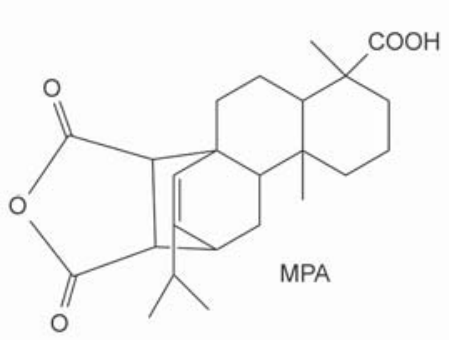

Dehydrodecarboxylation
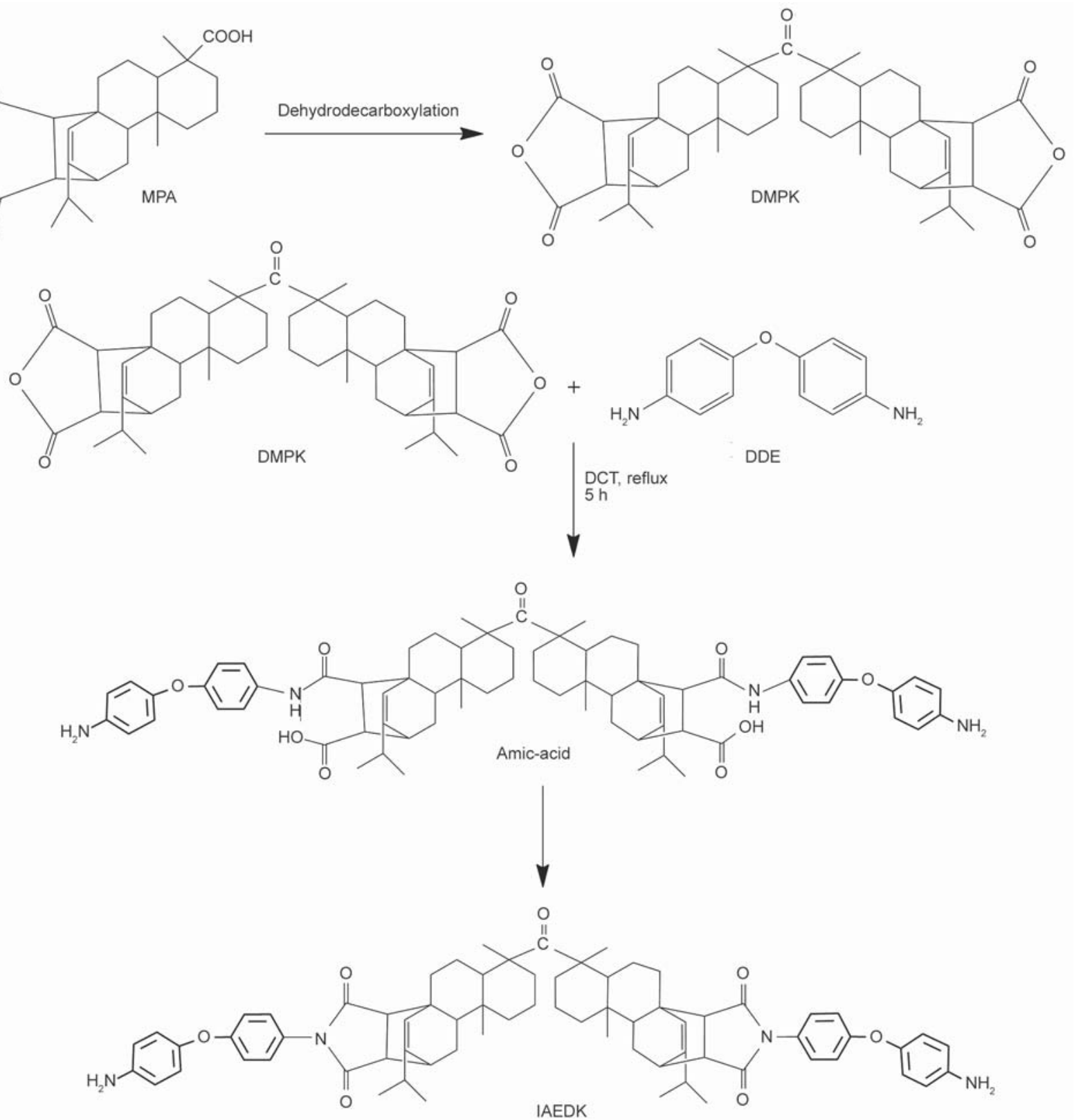

Figure 2. Synthetic route for IAEDK curing agent.

assigned to proton (2). Figure 6a displays the ${ }^{13} \mathrm{C}$-NMR spectrum of PEMPAE wherein the signals were observed at 180,175 and 173 ppm for carbonyl carbons of the ester groups at 5, 6 and 7, respectively. This confirms the esterification of the carboxylic acid group. The resonance signals observed at 121 and $130 \mathrm{ppm}$ are assigned to unsaturated carbons 3 and 4, respectively. The peaks due to carbon $\mathbf{1 , 2}$ and 8 of epoxide group are observed at 44, 51 and 72 ppm respectively, which proves the epoxidation of PEMPA. The chemical structure of the rosin modified imidoamine curing agent (IAEDK) was also confirmed by FTIR, ${ }^{1} \mathrm{H}-\mathrm{NMR}$, and ${ }^{13} \mathrm{C}-\mathrm{NMR}$. The FTIR spectrum (Figure $4 \mathrm{~b}$ ) of DMPK shows the disappearance of peak at $3300-3600 \mathrm{~cm}^{-1}$ for the carboxylic $-\mathrm{OH}$ present in MPA confirming the dimerization of MPA to DMPK. In the FTIR of IAEDK, the appearance of a peak at $1692 \mathrm{~cm}^{-1}$ for the $\mathrm{C}=\mathrm{O}$ of amide and disappearance of peaks due to anhydride $\mathrm{C}=\mathrm{O}$ stretching vibrations can be observed which confirms the imide bond formation. Also, two characteristic peaks at 3358 and $3325 \mathrm{~cm}^{-1}$ show the presence of $-\mathrm{NH}_{2}$ group. In the ${ }^{1} \mathrm{H}-\mathrm{NMR}$ of DMPK (Figure $5 \mathrm{~d}$ ), the disappearance of the signal at $11.6 \mathrm{ppm}$ for carboxylic acid proton in MPA confirms the dimerization reaction. Figure 5e shows the ${ }^{1} \mathrm{H}-\mathrm{NMR}$ spectrum of IAEDK wherein the peak at $5.5 \mathrm{ppm}$ is due to the proton (1) at unsaturated carbon and the signal at $4.1 \mathrm{ppm}$ attributes to the aromatic $-\mathrm{NH}_{2}$ protons (2) The protons (5) and (6) were characterized by signals 
which appeared at 3.1 and $2.9 \mathrm{ppm}$, respectively. The resonance signals observed in range $6.6-7.3$ ppm corresponds to the aromatic protons of benzene ring present in the imidoamine moiety. The ${ }^{13} \mathrm{C}$-NMR spectrum of imidoamine crosslinker is shown in Figure $6 \mathrm{~b}$. The signals due to the carbonyl carbon of ketone and cyclic imide can be observed at 185 ppm (carbon 1),
$178 \mathrm{ppm}$ (carbon 2) and $176 \mathrm{ppm}$ (carbon 3 ). The unsaturated carbons 8 and $\mathbf{6}$ show signals at 128 and $149 \mathrm{ppm}$, respectively. The aromatic carbon 7 bonded with $-\mathrm{NH}_{2}$ shows a peak at $142 \mathrm{ppm}$ and carbon 4 involved in ether linkage appears at $158 \mathrm{ppm}$.

The molecular weight determined by GPC and melting points of synthesized products are shown in

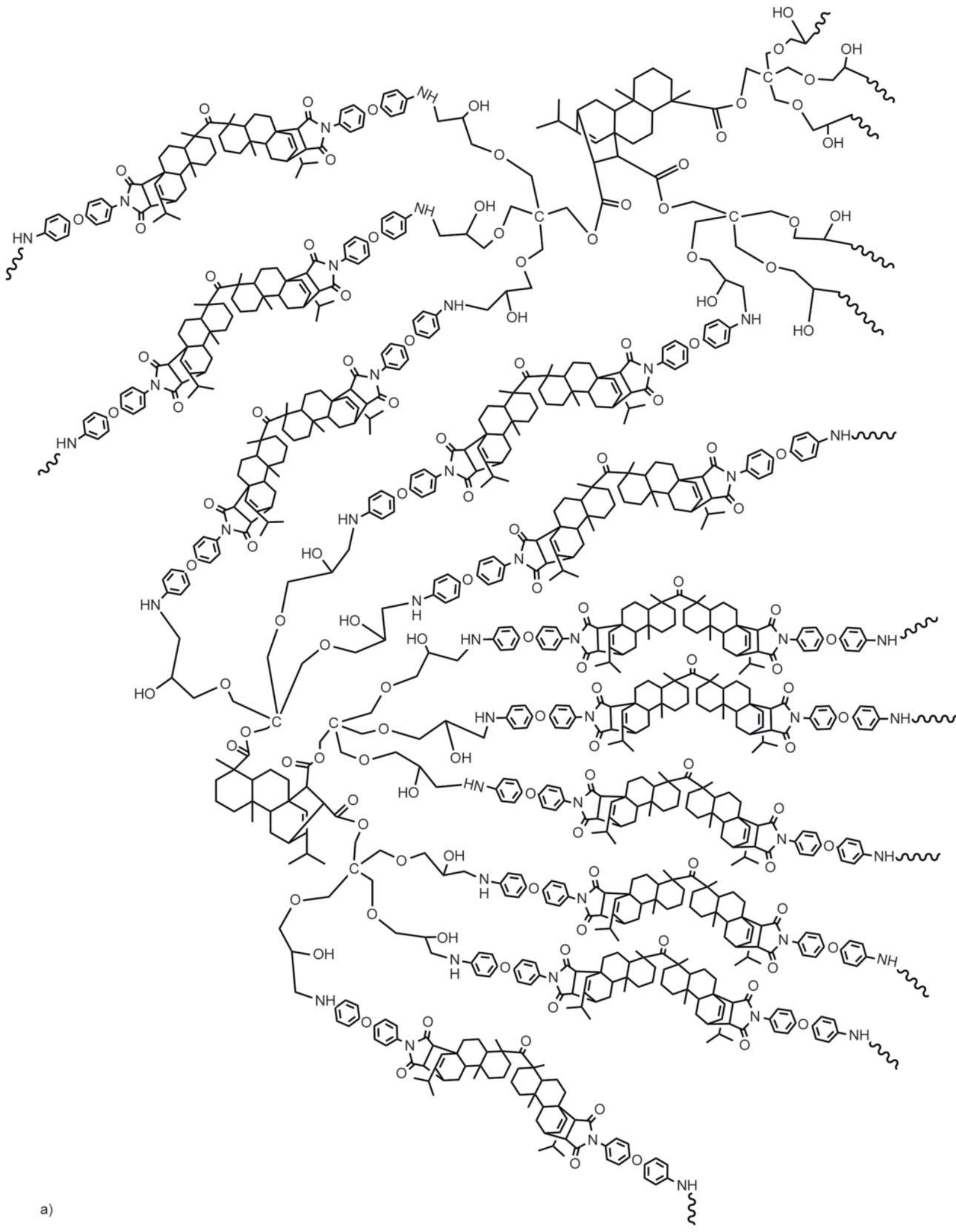




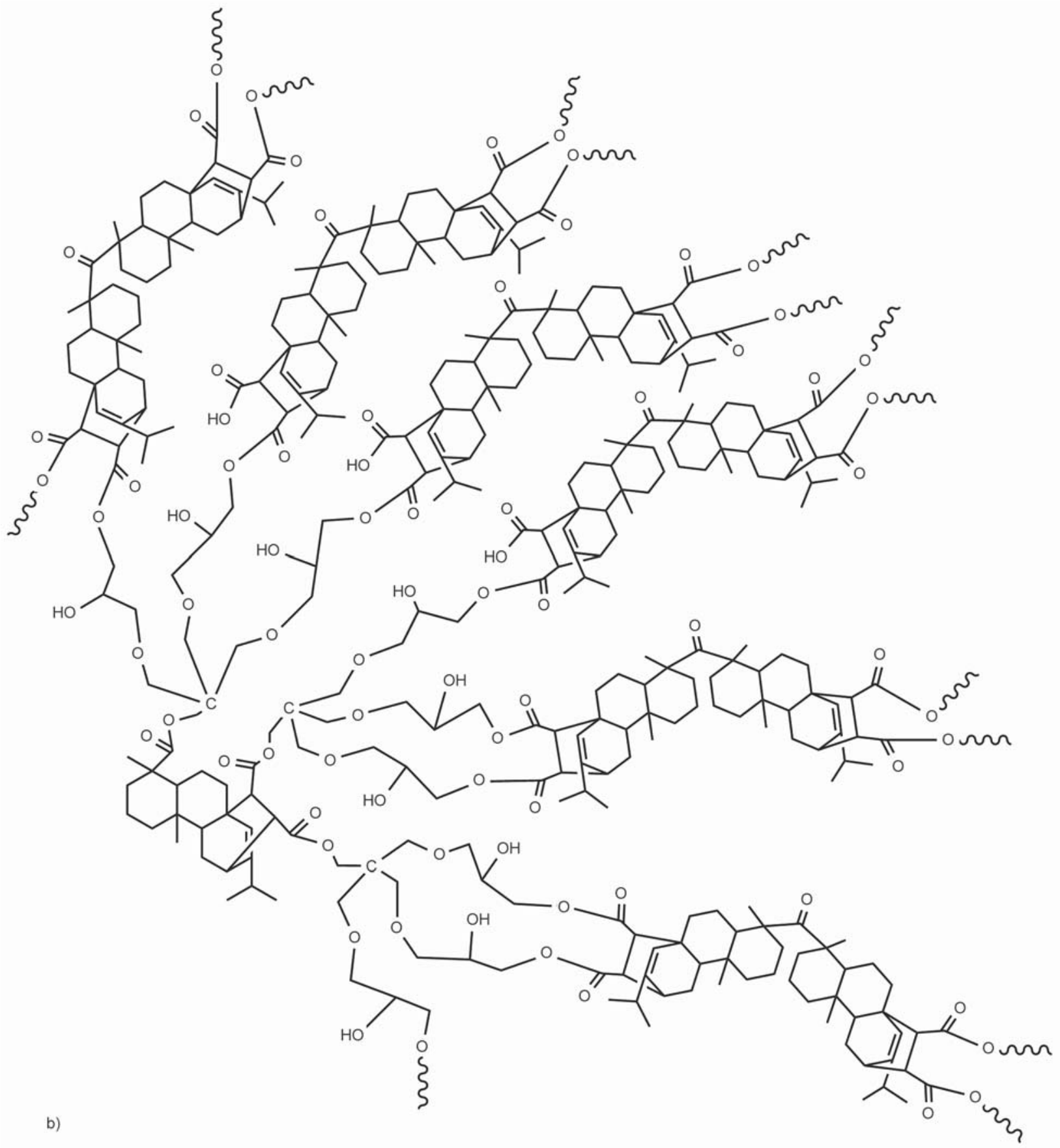

Figure 3. Proposed crosslinking of (a) PEMPAE epoxy resin with IAEDK and (b) PEMPAE epoxy resin with DMPK curing agents.

Table 1 and the typical GPC graph for PEMPAE epoxy resin is presented in Figure 7a giving the molecular weight of $1277.5 \mathrm{~g} / \mathrm{mol}$. The single peak appeared in the GPC graph, which shows the absence of side reactions during synthesis. The molecular weights of PEMPA adduct and PEMPAE epoxy resin were also determined using ${ }^{1} \mathrm{H}-\mathrm{NMR}$ analysis.

In order to determine the molecular weight of the epoxy, the hydroxyl functionality in PEMPA was known by the acetic anhydride/pyridine method [32]. The hydroxyl value obtained showed the presence of
9 hydroxyl groups. These values were also calculated from the ${ }^{1} \mathrm{H}-\mathrm{NMR}$ data by relating the integration of hydroxyl protons (proton 1) to that of the double bond proton (proton 3 ) (Figure 5b). Thus, the hydroxyl functionality was found to be 9 (11.26/ 1.25), which matches that obtained from a chemical titration procedure. This proves the formation of PEMPA molecule. The molecular weight was calculated to be $772.92 \mathrm{~g} / \mathrm{mol}$ according to the chemical structure of PEMPA which is similar to the value obtained from GPC graph. 

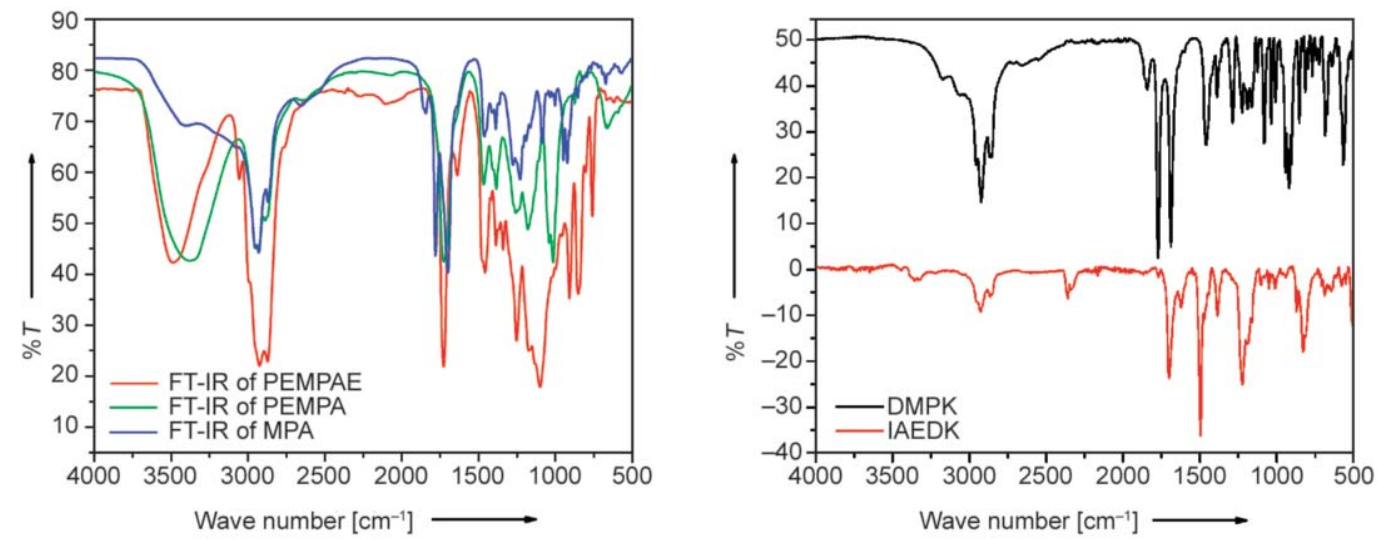

Figure 4. FTIR spectra of (a) MPA, PEMPA and PEMPAE (b) DMPK and IAEDK.

Similarly, the epoxide equivalent weight for PEMPAE epoxy resin was determined to be $151.23 \mathrm{~g} / \mathrm{eq}$ by pyridinium chloride method [33]. The epoxy functionality for PEMPAE was calculated by the formula, $E=1000 / E E W$, which comes out to be $6.6 \mathrm{eq} . / \mathrm{kg}$. The molecular weight formula can be given as
$(772.92+56 F)$, where 772.92 is the molecular weight of PEMPA, 56 is the molecular weight of one epoxy group and $F$ is the total epoxy functionality per molecule. Therefore, the epoxy functionality per molecule was calculated from the epoxy value $(E)$ determined by titration method using Equation (2): MPA
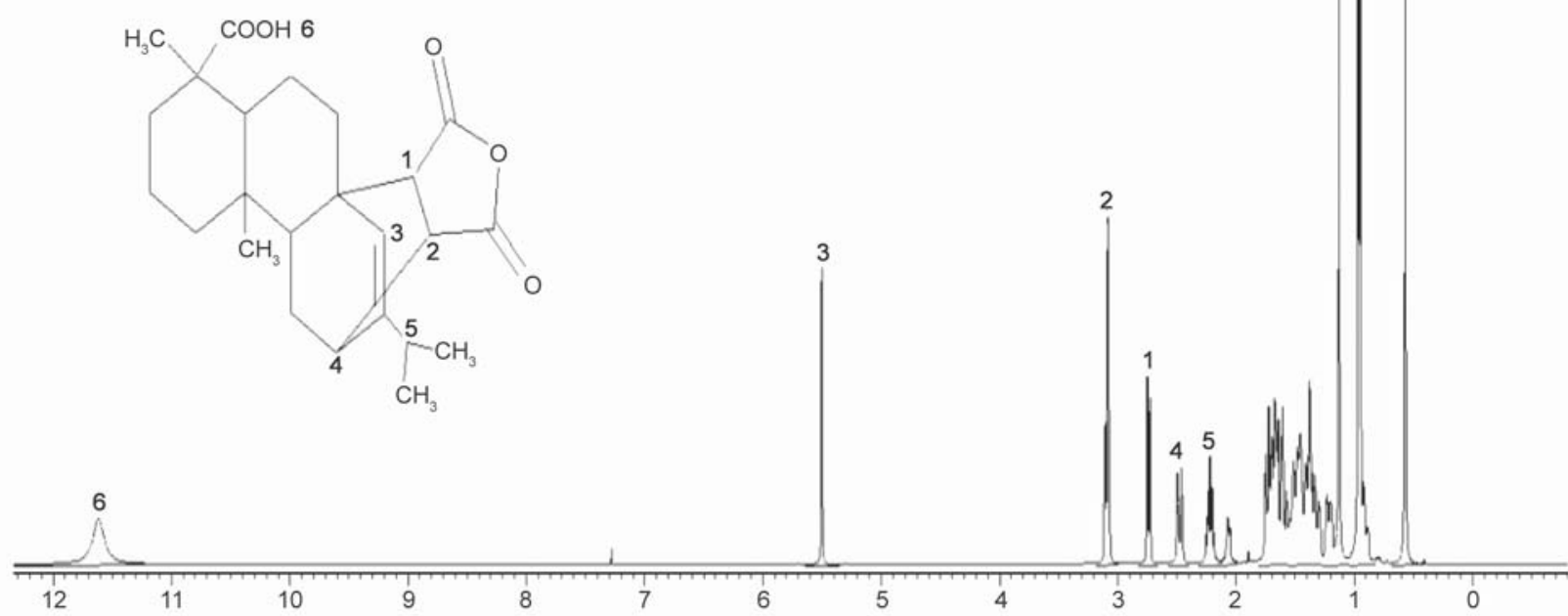

a) [ppm]

PEMPA<smiles>CC(C)C1=NC2(C(=O)OCC(CO)(CO)CO)CCC3C(C)(C(=O)OCC(CO)(CO)CO)CCCC3(C)C2CCC1(C)COC(CO)(CO)CO</smiles>

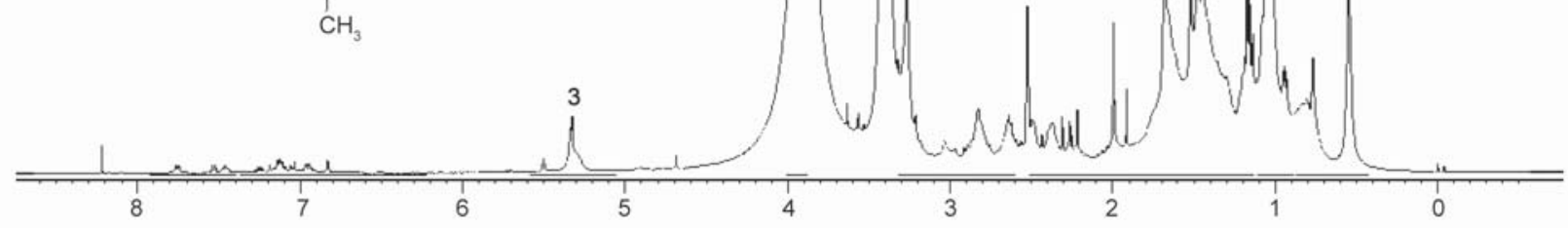

b)

[ppm] 


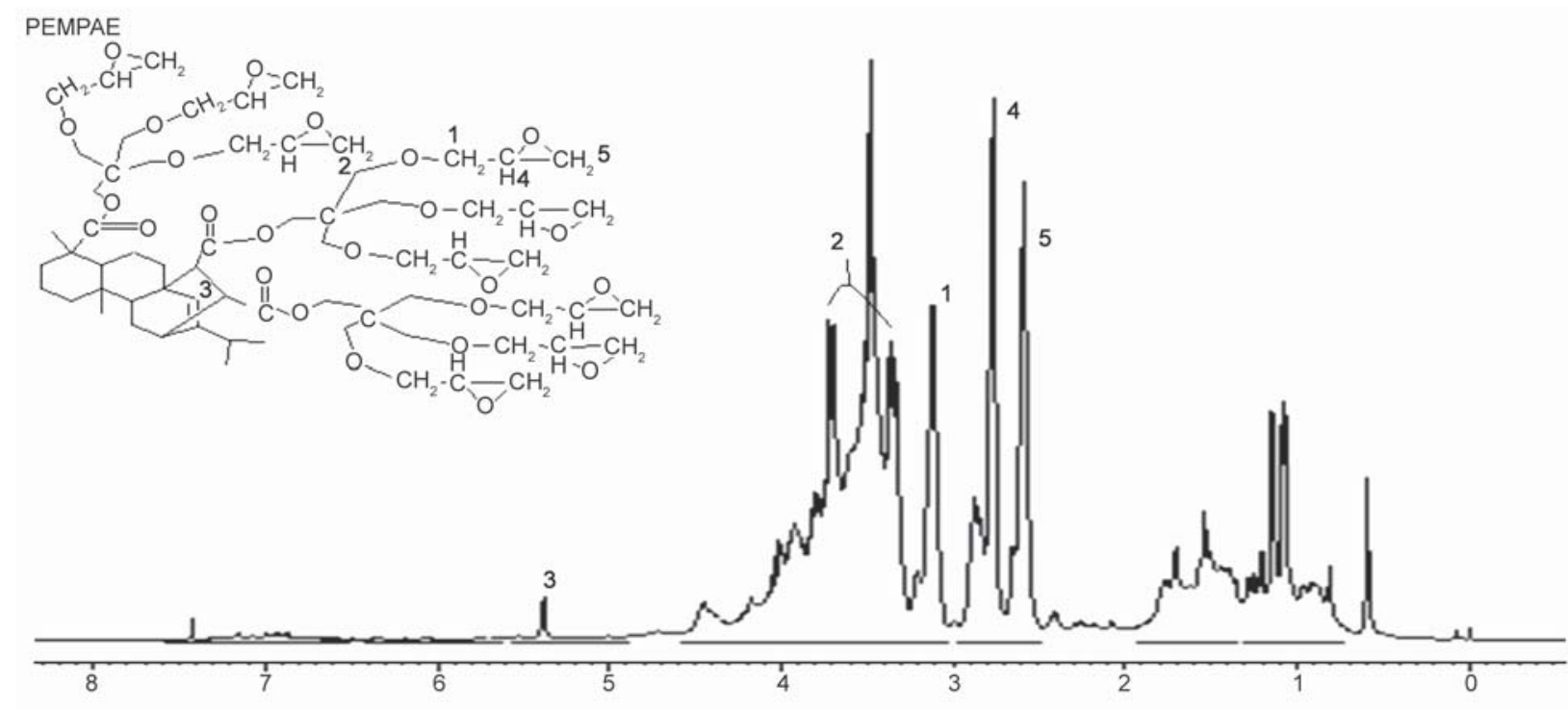

c)

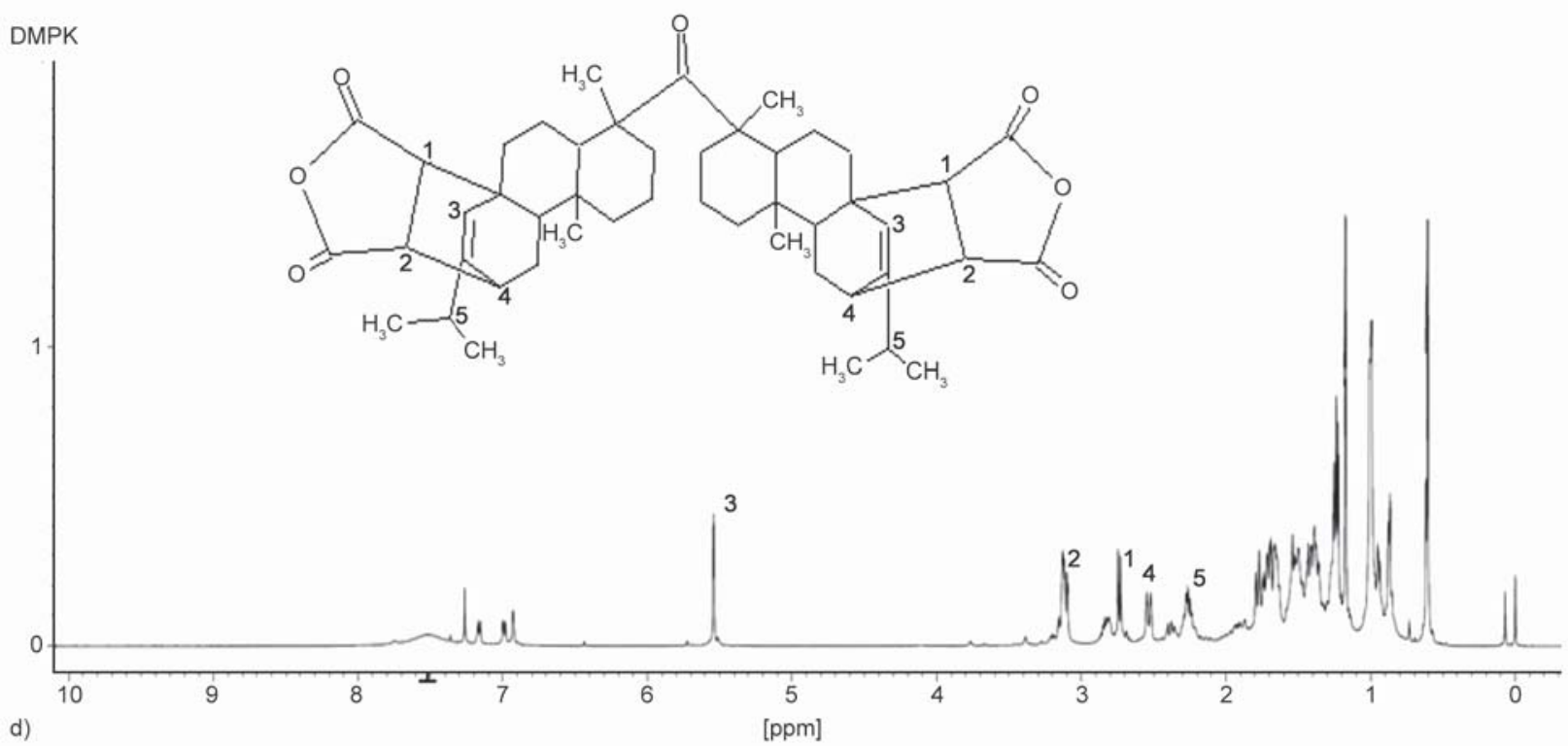

IAEDK

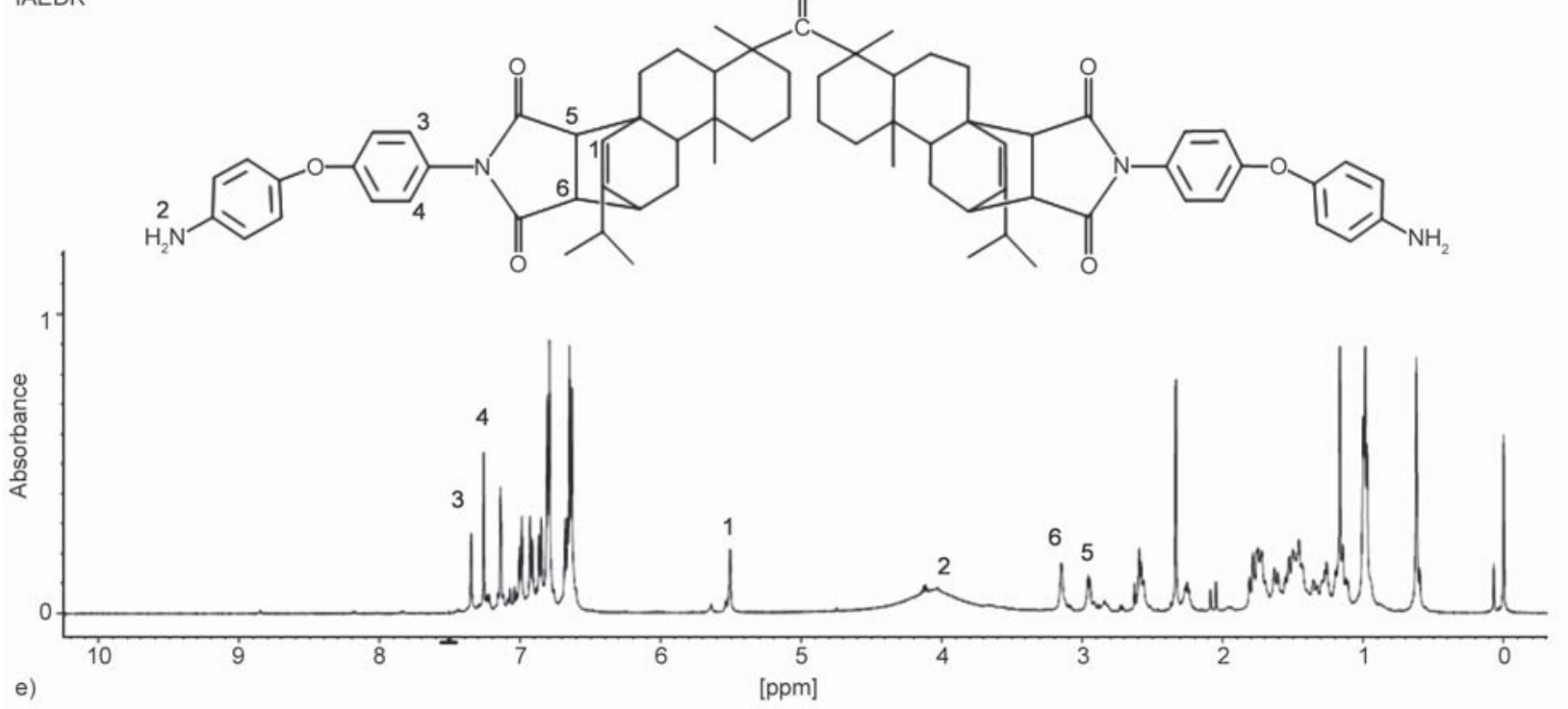

Figure 5. ${ }^{1} \mathrm{H}$ NMR spectra of (a) MPA, (b) PEMPA, (c) PEMPAE, (d) DMPK and (e) IAEDK. 


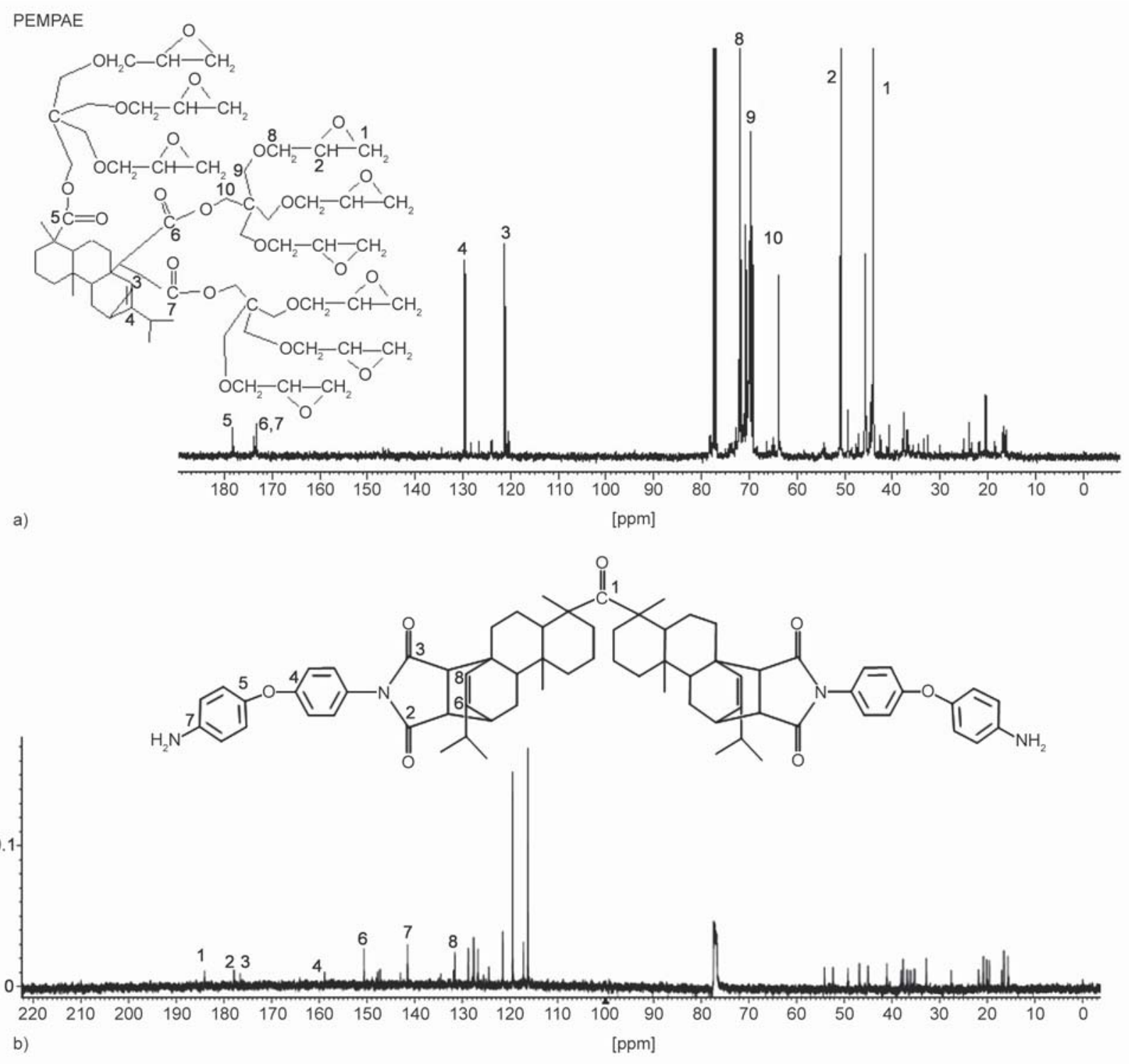

Figure 6. ${ }^{13} \mathrm{C}$ NMR spectra of (a) PEMPAE epoxy resin and (b) IAEDK curing agent.

$$
\begin{aligned}
F & =\frac{772.92 \cdot E}{1000-(56 \cdot E)}=\frac{772.92 \cdot 6.6}{1000-(56 \cdot 6.6)}= \\
& =8.09 \approx 8.1
\end{aligned}
$$

The epoxy functionality was also calculated via ${ }^{1} \mathrm{H}-\mathrm{NMR}$ analysis. It was determined from the ratio of integration of epoxy protons (proton 5) to the integration of double bond proton (proton 3 ) (Figure 5c). Thus, the number of epoxy groups is given by, $F=$ $(2.09 / 0.24)=8.7$, which comes to be almost equal to the value determined by the titration method. The molecular weight can be determined using the formula: Mol. Wt. $=(772.92+56 F)=(772.92+56 \cdot 8.7)=$ $1260.12 \mathrm{~g} / \mathrm{mol}$, which is comparable to the value determined by GPC graph.

The typical GPC graph for synthesized curing agent IAEDK is shown in Figure 7b. The molecular weight of $1056.2 \mathrm{~g} / \mathrm{mol}$ and polydispersity (PDI) of 1.06 was
Table 1. GPC determined molecular weights and melting points of synthesized products.

\begin{tabular}{|l|c|c|c|}
\hline \multirow{2}{*}{ Samples } & \multicolumn{2}{|c|}{$\begin{array}{c}\text { Weight average molecular weight, } \overline{\boldsymbol{M}}_{\mathbf{w}} \\
\text { [g/mol] }\end{array}$} & $\begin{array}{c}\text { Melting } \\
\text { point } \\
{\left[\begin{array}{c}\left.{ }^{\circ} \mathbf{C}\right] \\
\right.$\cline { 2 - 4 }\end{array}}\end{array} \\
\cline { 2 - 4 } & $\begin{array}{c}\text { Experimental } \\
\text { values }\end{array}$ & Theoretical values & 232 \\
\hline MPA & 398.67 & 400.51 & 120 \\
\hline PEMPA & 775.40 & 772.92 & - \\
\hline DEMPAE & 1277.50 & 1242.88 & 130 \\
\hline IAEDK & 796.40 & 739.01 & 145 \\
\hline
\end{tabular}

obtained from the graph. The GPC graph displays a single narrow peak which depicts the absence of side reactions. The molecular weight for imidoamine curing agent was also determined as $1104 \mathrm{~g} / \mathrm{mol}$ according to its chemical structure which is comparable to the value determined by GPC. The amine equivalent 


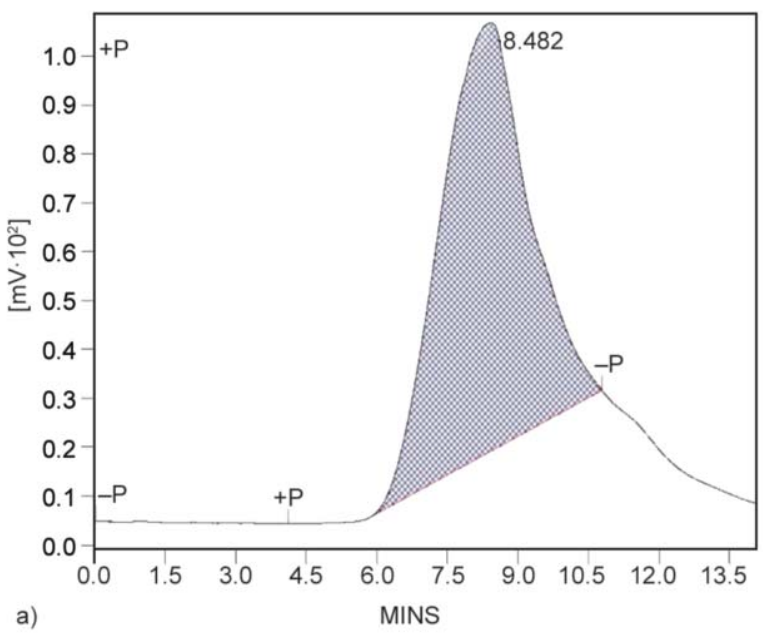

Figure 7. GPC of (a) PEMPAE and (b) IAEDK.

Table 2. Composition of different epoxy cured samples.

\begin{tabular}{|c|l|l|l|c|}
\hline S.No. & Epoxy & $\begin{array}{c}\text { Curing } \\
\text { agent }\end{array}$ & Sample Id & $\begin{array}{c}\text { Weight ratio } \\
\text { (Curing agent: } \\
\text { epoxy) }\end{array}$ \\
\hline 1. & PEMPAE & IAEDK & PDA & $3.3: 1$ \\
\hline 2. & PEMPAE & DMPK & PDK & $2.3: 1$ \\
\hline 3. & PEMPAE & DDE & PDE & $0.6: 1$ \\
\hline 4. & TMPAE & IAEDK & TDA & $2.7: 1$ \\
\hline 5. & TMPAE & DMPK & TDK & $1.9: 1$ \\
\hline 6. & TMPAE & DDE & TDE & $0.5: 1$ \\
\hline
\end{tabular}

weight (552 g/eq.) was also calculated for the IAEDK curing agent by taking a ratio of molecular weight to the number of available hydrogens per molecule. The epoxide equivalent and amine equivalent values were used for computing the stoichiometry of epoxy and curing agent for the curing reaction. Table 2 shows the appropriate curing agent to the epoxy weight ratio for six different samples using two epoxies (PEMPAE \& TMPAE) and three curing agents (IAEDK, DMPK \& DDE).

\subsection{Curing studies}

The curing behavior of the epoxy resins PEMPAE and TMPAE with different curing agents IAEDK,

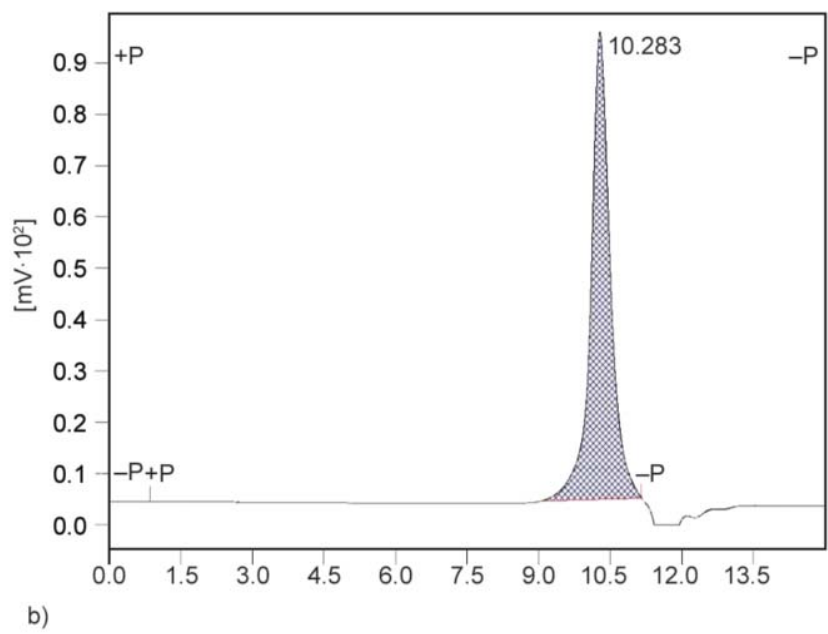

DMPK and DDE were carried out using Differential Scanning Calorimeter at a programmed heating rate of $10^{\circ} \mathrm{C} \cdot \mathrm{min}^{-1}$. Figure 8 a shows a typical DSC (exo up) curve for PEMPAE epoxy resin with IAEDK curing agent in the temperature range $70-225^{\circ} \mathrm{C}$. The DSC curing temperatures and energy corresponding to exotherms $(\Delta H)$ for all the cured epoxy systems are summarized in Table 3 . The onset and peak temperatures depicted from the DSC curves indicate the reactivity of the curing agents with epoxy resins throughout the curing reactions, i.e. lower values of onset exothermic temperature shows more reactivity of the curing agent towards the epoxy resin. The exothermic transition for the sample PEMPAEIAEDK (PDA) ensure lowest curing temperature with $72^{\circ} \mathrm{C}$ onset, $117^{\circ} \mathrm{C}$ peak, and $167^{\circ} \mathrm{C}$ endset temperatures. This signifies that the imidoamine curing agent offers the highest reactivity towards epoxy resin among all the three curatives. The amine group reacts with epoxide ring via nucleophilic addition reaction. Figure 3 a shows the proposed network structure formed by crosslinking of imidoamine curing agent with PEMPAE epoxy resin. The reason for the highest reactivity of imidoamine curing agent must

Table 3. DSC results of cured epoxy resin samples.

\begin{tabular}{|l|c|c|c|c|}
\hline \multicolumn{1}{|c|}{ Name of sample } & $\begin{array}{c}\text { Onset temperature } \\
{\left[{ }^{\circ} \mathbf{C}\right]}\end{array}$ & $\begin{array}{c}\text { Peak temperature } \\
{\left[{ }^{\circ} \mathbf{C}\right]}\end{array}$ & $\begin{array}{c}\text { Endset temperature } \\
{\left[{ }^{\circ} \mathbf{C}\right]}\end{array}$ & $\begin{array}{c}\text { Enthalpy change, } \Delta \boldsymbol{H} \\
{[\mathbf{J} / \mathbf{g}]}\end{array}$ \\
\hline PEMPAE+IAEDK & 72 & 117 & 167 & 21.60 \\
\hline PEMPAE+DMPK & 112 & 172 & 224 & 25.30 \\
\hline PEMPAE+DDE & 80 & 140 & 185 & 33.40 \\
\hline TMPAE+IAEDK & 96 & 118 & 134 & 20.20 \\
\hline TMPAE+DMPK & 120 & 180 & 220 & 16.51 \\
\hline TMPAE+DDE & 80 & 135 & 185 & 24.80 \\
\hline
\end{tabular}



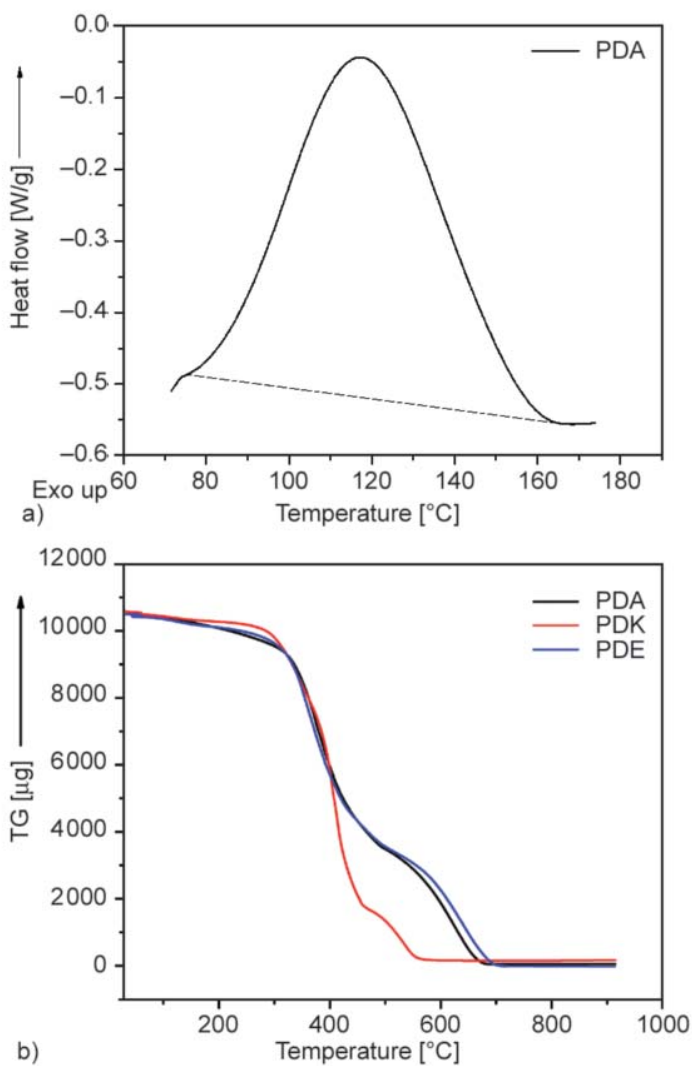

b)

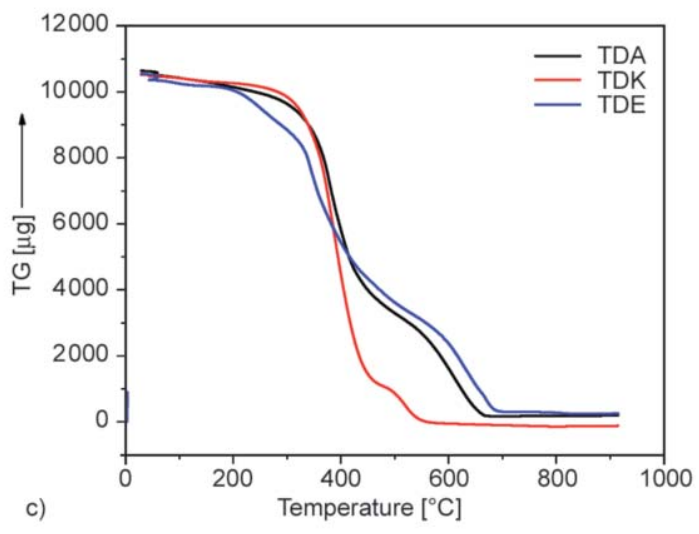

Figure 8. (a) DSC Scan for curing of rosin epoxy resin PEMPAE with IAEDK curing agent (b) TGA curves of epoxy PEMPAE cured with different curing agents and (c) TGA curves of epoxy TMPAE cured with different curing agents.

be the increased nucleophilicity of amine groups due to the introduction of rosin moiety which showed an electron-donating effect. Moreover, the cycloaliphatic phenanthrane ring reduces the aromaticity of imidoamine curing agent hereby lowering its melting temperature than that of aromatic DDE curing agent. Chiu et al. [34] found that the aromatic amine curing agents shows high-temperature curing than that of aliphatic amine curing agents owing to their chemical structures and electron-withdrawing properties. Thus, less aromatic IAEDK shows more reactivity and low temperature curing towards rosin epoxy resins. For commercial curing agent DDE, curing with rosin epoxy resins starts at $80^{\circ} \mathrm{C}$ which is higher than imidoamine curing agent. Burkanudeen and Ramesh [35] reported the DSC curing study of DGEBA (commercial epoxy resin) with DDE that exhibited curing onset temperature $140^{\circ} \mathrm{C}$ and peak temperature $159^{\circ} \mathrm{C}$. These results are much higher than that obtained by rosin-based epoxy resins PEMPAE and TMPAE with DDE, an observation that shows higher reactivity of rosin-based epoxy resins with DDE as compared to commercial DGEBA epoxy resin. Furthermore, anhydride curing agent DMPK exhibits a higher curing temperature than aminebased curing agents. An anhydride group reacts with two epoxy groups to give hydroxyl diester which further reacts with excess epoxy groups to form a crosslinked polyester network [26]. Figure $3 b$ shows proposed crosslinked network structure for DMPK curing agent with PEMPAE epoxy resin. This homopolymerization of epoxy results in high temperature curing exotherm for epoxy-anhydride curing system. Also, the Pentaerythritol based epoxy resin showed low temperature curing i.e. higher reactivity than trimethylol based epoxy resin because of the greater number of epoxy groups in PEMPAE. DTA run was carried out on the cured samples in order to check for residual curing. The absence of residual curing exotherm indicated the samples to be completely cured. Additionally, the enthalpy of the reaction $(\Delta H)$ is also observed to be lower for the imidoamine and DMPK cured epoxy samples than the DDE cured epoxy which signifies the higher degree of curing or crosslinking in epoxy resins cured with rosin-based curing agents [36].

\subsection{Thermal behavior of cured epoxy systems}

The study of thermal degradation of epoxy thermosets is significant in analyzing the use temperature range for the epoxy system. For this investigation, TGA is considered to be the most convenient and commonly employed technique for isothermally cured epoxy systems. Table 4 summarizes the relative thermal stability for different samples with respect to initial decomposition temperature (IDT), the temperature at which maximum decomposition occurs $\left(T_{\max }\right)$, final decomposition temperature (FDT), weight loss [\%] at maximum decomposition temperature, activation energies, temperatures at which $5,10,20 \%$ weight loss occurs and char yield [\%] at $600{ }^{\circ} \mathrm{C}$. Figure $8 \mathrm{~b}$ 
Table 4. TGA studies of various cured epoxy compounds.

\begin{tabular}{|c|c|c|c|c|c|c|c|c|c|}
\hline \multirow[t]{2}{*}{ Name of sample } & \multirow{2}{*}{$\begin{array}{l}I D T \\
{\left[{ }^{\circ} \mathrm{C}\right]}\end{array}$} & \multirow{2}{*}{$\begin{array}{l}T_{\max } \\
{\left[{ }^{\circ} \mathbf{C}\right]}\end{array}$} & \multirow{2}{*}{$\begin{array}{l}F D T \\
{\left[{ }^{\circ} \mathrm{C}\right]}\end{array}$} & \multicolumn{3}{|c|}{$\begin{array}{c}\text { Temperatures at weight loss \% } \\
{\left[{ }^{\circ} \mathrm{C}\right]}\end{array}$} & \multirow{2}{*}{$\begin{array}{c}\text { Weight loss at } \\
T_{\max } \\
{[\%]}\end{array}$} & \multirow{2}{*}{$\begin{array}{c}\text { Activation } \\
\text { energy, } \Delta E \\
{[\mathrm{KJ} / \mathrm{mol}]}\end{array}$} & \multirow{2}{*}{$\begin{array}{c}\text { Char yield at } \\
600^{\circ} \mathrm{C} \\
{[\%]}\end{array}$} \\
\hline & & & & $5 \%$ & $10 \%$ & $20 \%$ & & & \\
\hline PEMPAE+IAEDK & 246 & 379 & 524 & 263 & 304 & 350 & 66 & 89.8 & 15.2 \\
\hline PEMPAE+DMPK & 222 & 405 & 484 & 279 & 313 & 348 & 50 & 98.0 & 0.5 \\
\hline PEMPAE+DDE & 174 & 354 & 516 & 245 & 313 & 348 & 77 & 73.1 & 22.0 \\
\hline TMPAE+ IAEDK & 230 & 378 & 520 & 246 & 305 & 355 & 68 & 86.0 & 17.7 \\
\hline TMPAE+DMPK & 210 & 388 & 476 & 281 & 322 & 352 & 52 & 96.0 & 1.5 \\
\hline TMPAE+DDE & 154 & 343 & 468 & 202 & 250 & 323 & 73 & 59.8 & 21.6 \\
\hline
\end{tabular}

and 8c shows the TGA curves for epoxy resins PEMPAE and TMPAE cured with IAEDK, DMPK, and DDE curing agents, respectively. The epoxies cured with IAEDK exhibits maximum thermal stability with $I D T 246^{\circ} \mathrm{C}$ and $T_{\max } 349^{\circ} \mathrm{C}$ for PDA and IDT $230^{\circ} \mathrm{C}$ and $T_{\max } 378^{\circ} \mathrm{C}$ for TDA. The reason may be attributed to three dimensional crosslinked network structure established by multifunctional epoxy resin with diamine curing agent and also due to high ordered packing structure formed by planar phenanthrane and rigid phenyl rings present in curing agent moiety. El-Ghazawy et al. [21] have reported a fully rosin-based system in which tetraglycidyl epoxy synthesized by epoxidation of dipimaryl ketone (DMPK) was cured with synthesized diacid crosslinker that shows high thermal stability than that of DGEBA epoxy system cured with commercial diamine crosslinker. They found that the rosin epoxy system was stable till $360^{\circ} \mathrm{C}$ and this high stability is due to the well-ordered crosslinking and analogy in structures of both epoxy and curing agent. Furthermore, the incorporation of imide units into the curing agent molecule greatly influenced the thermal performance of the cured epoxy system. Liu et al. [25] observed significantly improved thermal stability of epoxy-diacid system via imide units present in the rosin derived diacid crosslinker. The epoxy samples cured with anhydride type DMPK curing agent showed thermal stability as good as imidoamine curing agent and a slow degradation rate at an early phase of decomposition was found but a rapid thermal decomposition was observed as the scanning temperature exceeds $400^{\circ} \mathrm{C}$. The samples cured with DDE commercial curing agent come out to be thermally least stable and shows $I D T 174^{\circ} \mathrm{C}$ and $T_{\max }$ $354^{\circ} \mathrm{C}$. These values were compared to the previously reported study of Patel et al. [37] where the authors used DGEBA, phenyl based epoxy resin with DDE that exhibited $I D T 148^{\circ} \mathrm{C}$ and $10 \%$ weight loss temperature of $240^{\circ} \mathrm{C}$ that shows lesser thermal stability of commercial DGEBA/DDE as compared to rosinbased PEMPAE epoxy resin. Also, in case of pentaerythritol based epoxy resin, higher $T_{\max }$ values were observed which may be attributed to the greater epoxy functionality producing highly crosslinked network than trimethylol based epoxy resin. These results show that rosin derived imidoamine and DMPK curing agents give rise to more stable epoxy thermosets as compared to commercial curing agents. The study shows that the thermal stability of cured resins depends upon the structure of curing agents and the crosslinking sites of two component epoxy matrix.

The activation energy of the thermal degradation reaction was calculated from TGA data by a method independent of heating rates and sample size reported by Dharwadkar et al. [38]. The equation for $E_{\mathrm{a}}$ is given by Equation (3):

$\ln \left[\ln (1-\alpha)^{-1}\right]=\frac{E_{a} \cdot 100 \theta}{R T_{\mathrm{i}}^{2}\left(T_{\mathrm{f}}-T_{\mathrm{i}}\right)}+C$

where $\alpha$ is degrading fraction; $T_{\mathrm{i}}$ is inception temperature; $T_{\mathrm{f}}$ is inflection temperature; $\theta$ is the difference of maximum temperature and temperature under consideration; $R$ is gas constant; $C$ is constant. $E_{\mathrm{a}}$ is evaluated by plotting $\ln \left[\ln (1-\alpha)^{-1}\right]$ vs $\theta$ giving a straight line with slope $m$ (Equation (4)):

$m=\frac{E_{a} \cdot 100}{R T_{\mathrm{i}}^{2}\left(T_{\mathrm{f}}-T_{\mathrm{i}}\right)}$

Thus activation energies of decomposition for all the samples were evaluated by Equations (3) and (4) and listed in Table 4. It can be seen that the epoxies cured with rosin-based curing agents showed a greater value of activation energy than that of the commercial one. Also, anhydride type curing agent (DMPK) showed the highest value of $E_{\mathrm{a}}$ among all due to the strong diester bonds which tend to enhance the thermal stability. 


\subsection{Mechanical analysis of cured epoxy systems}

Mechanical properties of cured epoxy systems entirely depend upon the chemical structures of both epoxy and hardener and their degree of crosslinking. Keeping this in view, the two-component coating system was designed to generate cured resin with high mechanical properties. For studying the mechanical behavior of cured epoxy resins, compression, flexural and tensile tests were performed and results have been summarized in Table 5. The data illustrates that epoxy cured with rosin curing agents exhibited higher mechanical strength as compared to commercial DDE. Furthermore, imidoamine cured epoxy offered best outcomes for tensile, compression and flexural strength which must be owing to the strong polar interactions of imide, esters and carbonyl groups present in the crosslinked network which tends to reduce the chain mobility and resist the matrix deformation. In the case of DMPK cured resin, mechanical strength values are lesser than the former because of the brittle nature of the dimerized rosin moiety present in the crosslinker. Moreover, pentaerythritol based epoxy system showed better mechanical behavior than trimethylol one that reflects higher

Table 5. Mechanical tests of cured epoxy samples.

\begin{tabular}{|l|c|c|c|}
\hline Name of sample & $\begin{array}{c}\text { Compression } \\
\text { strength } \\
{[\mathbf{M P a}]}\end{array}$ & $\begin{array}{c}\text { Flexural } \\
\text { strength } \\
{[\mathbf{M P a}]}\end{array}$ & $\begin{array}{c}\text { Tensile } \\
\text { strength } \\
{[\mathbf{M P a}]}\end{array}$ \\
\hline PEMPAE+IAEDK & 80.7 & 82.8 & 28.1 \\
\hline PEMPAE+DMPK & 37.8 & 46.8 & 16.4 \\
\hline PEMPAE+DDE & 20.2 & 35.7 & 13.5 \\
\hline TMPAE+IAEDK & 75.7 & 49.1 & 27.5 \\
\hline TMPAE+DMPK & 24.0 & 46.5 & 14.5 \\
\hline TMPAE+DDE & 14.7 & 29.1 & 10.4 \\
\hline
\end{tabular}

crosslinking and amplified polymer chain interactions due to more epoxy functionality of PEMPAE resin. The study shows that the rosin-based epoxy and curing agent system can be a substitute for the incumbent petroleum-based systems.

\subsection{Chemical resistance of cured epoxy systems}

Chemical resistance of the cured epoxy systems was assessed by subjecting the cured epoxy coated steel specimens to the chemical environment of the acid, base, and salt in terms of \% weight loss. For this study, specimens were immersed in $1 \mathrm{M} \mathrm{HCl}, 1 \mathrm{M}$ $\mathrm{NaCl}$ and $1 \mathrm{M} \mathrm{NaOH}$ aqueous solutions for 90 days and weight loss was noted after a period of 30, 60 and 90 days of immersion. Table 6 shows the results of chemical resistance for the epoxy cured samples which demonstrate that imidoamine cured epoxy sample is the most resistant to the chemical environment. The existence of a highly crosslinked network must be the ultimate factor that prevents the cured sample from solvent attack. Also, the presence of hydrogen bonding and polar groups in the polymer chains greatly affects the diffusion of solvent molecules. The high chemical resistance in the case of imidoamine cured sample indicates the high degree of crosslinking of imidoamine curing agent with pentaerythritol based epoxy resin [39]. Atta et al. [23] performed chemical resistance tests on epoxy resins cured with amine curing agents and found that the rosin-based epoxy binders show more resistance to acidic and alkaline solutions due to highly crosslinked networks which reduces its environmental exposure. Likewise, the DMPK cured resins also exhibited good solvent resistance as compared to commercial DDE cured

Table 6. Chemical resistance of cured epoxy samples in terms of \% weight loss.

\begin{tabular}{|c|c|c|c|c|c|c|c|}
\hline \multirow[b]{2}{*}{$\begin{array}{c}\text { Aqueous } \\
\text { solution (1M) }\end{array}$} & \multirow[b]{2}{*}{ No. of days } & \multicolumn{6}{|c|}{ Samples } \\
\hline & & $\begin{array}{c}\text { PEMPAE+ } \\
\text { IAEDK } \\
\text { weight loss } \\
{[\%]}\end{array}$ & $\begin{array}{c}\text { PEMPAE+ } \\
\text { DMPK } \\
\text { weight loss } \\
{[\%]}\end{array}$ & $\begin{array}{c}\text { PEMPAE+ } \\
\text { DDE } \\
\text { weight loss } \\
{[\%]}\end{array}$ & $\begin{array}{c}\text { TMPAE + } \\
\text { IAEDK } \\
\text { weight loss } \\
{[\%]}\end{array}$ & $\begin{array}{c}\text { TMPAE + } \\
\text { DMPK } \\
\text { weight loss } \\
{[\%]}\end{array}$ & $\begin{array}{c}\text { TMPAE + } \\
\text { DDE } \\
\text { weight loss } \\
{[\%]}\end{array}$ \\
\hline \multirow{3}{*}{$\mathrm{HCl}$} & 30 & 2.3 & 2.9 & 4.8 & 4.4 & 2.9 & 4.9 \\
\hline & 60 & 3.8 & 4.3 & 6.6 & 3.9 & 5.1 & 7.2 \\
\hline & 90 & 5.1 & 6.2 & 11.4 & 5.4 & 6.5 & 11.8 \\
\hline \multirow{3}{*}{$\mathrm{NaOH}$} & 30 & 2.9 & 3.1 & 4.6 & 3.5 & 3.8 & 4.9 \\
\hline & 60 & 4.2 & 4.8 & 6.9 & 4.5 & 4.9 & 7.3 \\
\hline & 90 & 5.7 & 6.6 & 12.2 & 6.3 & 7.1 & 12.8 \\
\hline \multirow{3}{*}{$\mathrm{NaCl}$} & 30 & 2.5 & 2.7 & 3.5 & 2.9 & 3.9 & 5.1 \\
\hline & 60 & 3.9 & 4.5 & 6.8 & 4.1 & 5.3 & 7.6 \\
\hline & 90 & 5.5 & 6.5 & 11.9 & 5.8 & 6.9 & 12.3 \\
\hline
\end{tabular}


resins which is referred to the crosslinked polyester network formed by homopolymerization of epoxy functionality with anhydride groups.

\subsection{Surface morphology analysis by SEM}

Scanning electron microscopy (SEM) was used to analyze the destruction caused to the epoxy cured samples exposed to the chemical environment. The physical changes or surface morphology triggered by immersing the cured samples in different chemical solutions were observed by SEM images. The images in Figure 9a display the surface morphology of cured samples before immersion i.e. untreated with chemical solutions, whereas the images in Figure $9 \mathrm{~b}$ show the surface changes that occurred after dipping in $1 \mathrm{M} \mathrm{HCl}$ solution. The images clearly show
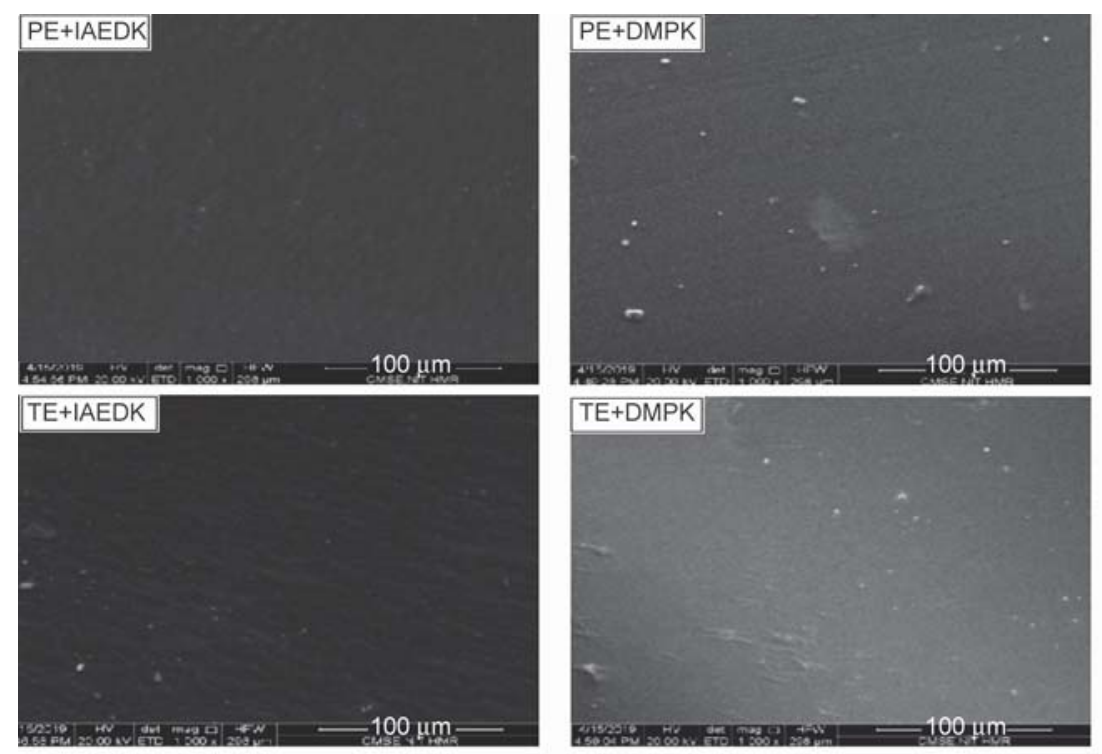

a)
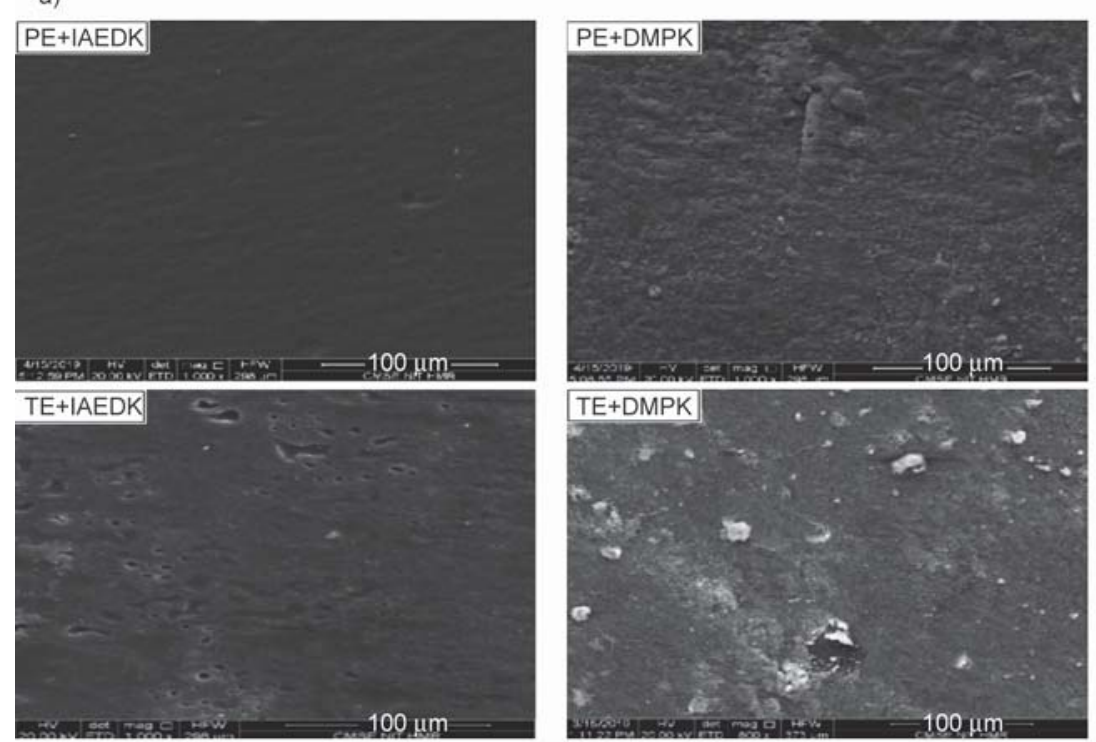

that the sample cured with imidoamine curing agent exhibited the least physical deterioration and were found to be most stable in a particular chemical environment. Besides this, the images for DDE cured samples show visible changes at the surface by the attack of the acidic solution. The signs of chemical corrosion can be seen as the cracks and roughening of the surface of cured resins which were smooth earlier [40]. These results ascertained that rosin epoxy cured with rosin imidoamine curing agent can be a substitute for coating application.

\section{Conclusions}

Rosin based two-component coating system; multifunctional epoxy resin (PEMPAE) and bifunctional imidoamine curing agent (IAEDK) were synthesized
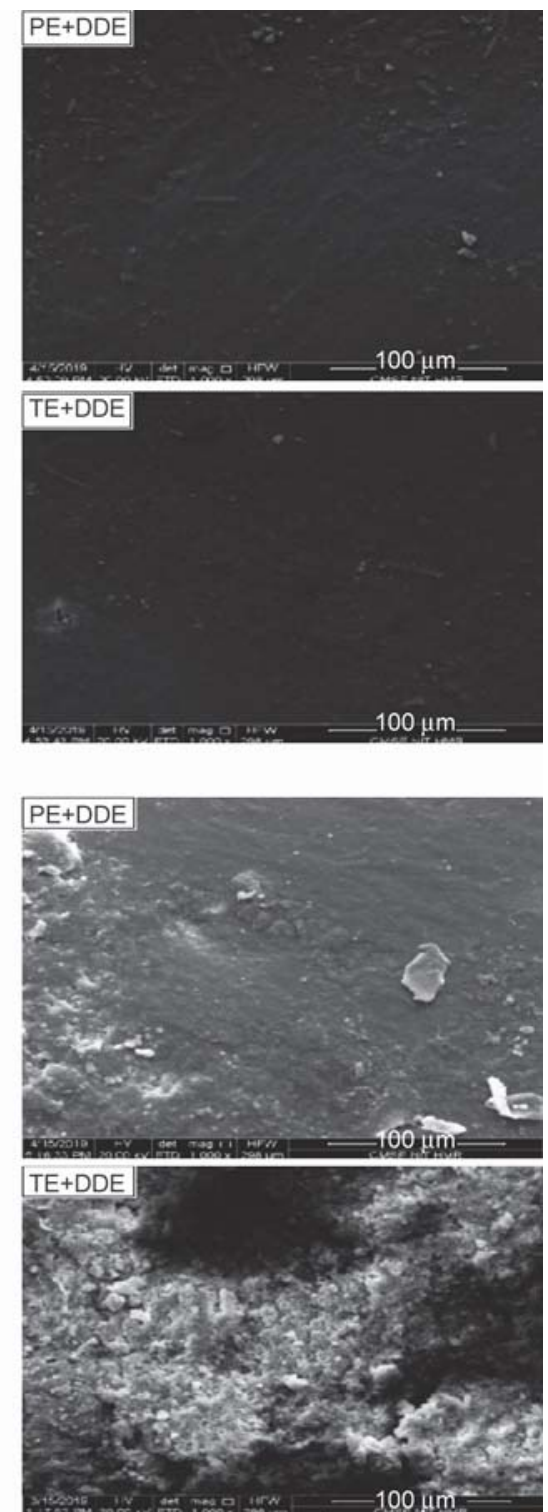

b)

Figure 9. SEM images of cured epoxy resins (a) before immersion in chemical solutions and (b) after immersion in $1 \mathrm{M} \mathrm{HCl}$. 
and their structural confirmation was done using FTIR, ${ }^{1} \mathrm{H}-\mathrm{NMR}$ and ${ }^{13} \mathrm{C}$-NMR spectroscopic methods. Curing dynamics and thermal performance of rosin epoxy resin cured with imidoamine curing agent were studied and compared with epoxy system cured with synthesized anhydride type DMPK and commercial amine type DDE crosslinkers. The results revealed that imidoamine cured epoxy system exhibits low curing temperature i.e. high reactivity and high thermal performance than that of its synthetic precursors. Mechanical tests and chemical resistance were also performed and the bio-based cured system was found to be more resistant to the chemical environment and possessed better mechanical strength as imidoamine crosslinker imparts a high degree of crosslinking to the cured epoxy system. The surface morphology of cured samples exposed to chemicals also validates the chemical resistance analysis. Owing to the thermal, chemical and mechanical outcomes, fully bio-based epoxy systems are found to be a promising substitute to petrochemical coating materials that can address the environmental concerns too.

\section{Acknowledgements}

We would like to acknowledge Director, National Institute of Technology Hamirpur (H.P.) India for providing basic laboratory facilities and CMSE NIT Hamirpur for instrumental assistance. The authors are also grateful for financial support from the Department of Science and Technology, New Delhi, India (DST/SSTP/HP/481).

\section{References}

[1] Coppen J. W., Hone G. A.: Gum naval stores: Turpentine and rosin from pine resin. Food and Agriculture Organisation of the United Nations, Rome (1995).

[2] Maiti S., Ray S. S., Kundu A. K.: Rosin: A renewable resource for polymers and polymer chemicals. Progress in Polymer Science, 14, 297-338 (1989).

https://doi.org/10.1016/0079-6700(89)90005-1

[3] May C.: Epoxy resins: Chemistry and technology. CRC Press, United States (1987).

[4] Jin F-L., Li X., Park S-J.: Synthesis and application of epoxy resins: A review. Journal of Industrial and Engineering Chemistry, 29, 1-11 (2015).

https://doi.org/10.1016/j.jiec.2015.03.026

[5] Kiran V., Gaur B.: Curing and thermal behavior of epoxy resins of hexafluoro-bisphenol-A and bisphenol-A. Polímeros, 26, 11-20 (2016).

https://doi.org/10.1590/0104-1428.2041
[6] Wan J., Li C., Bu Z-Y., Xu C-J., Li B-G., Fan H.: A comparative study of epoxy resin cured with a linear diamine and a branched polyamine. Chemical Engineering Journal, 188, 160-172 (2012).

https://doi.org/10.1016/j.cej.2012.01.134

[7] Lakshmi B., Shivananda K. N., Mahendra K. N.: Synthesis, characterization and curing studies of thermosetting epoxy resin with amines. Bulletin of the Korean Chemical Society, 31, 2272-2278 (2010).

https://doi.org/10.5012/bkcs.2010.31.8.2272

[8] Sharma P., Choudhary V., Narula A. K.: Curing of epoxy resin using imide-amines. Journal of Applied Polymer Science, 101, 3503-3510 (2006).

https://doi.org/10.1002/app.24580

[9] Ren R., Xiong X., Ma X., Liu S., Wang J., Chen P., Zeng Y.: Isothermal curing kinetics and mechanism of DGEBA epoxy resin with phthalide-containing aromatic diamine. Thermochimica Acta, 623, 15-21 (2016). https://doi.org/10.1016/j.tca.2015.11.011

[10] Zhang J.: Rosin-based chemicals and polymers. Rapra, Shrewsbury (2012).

[11] Gandini A.: Epoxy polymers based on renewable resources. in 'Epoxy polymers: New materials and innovation' (eds.: Pascault J-P., William R. J. J.) Wiley, Weinheim, 55-78 (2010). https://doi.org/10.1002/9783527628704.ch4

[12] Thanawala K., Mutneja N., Khanna A. S., Singh Raman R. K.: Development of self-healing coatings based on linseed oil as autonomous repairing agent for corrosion resistance. Materials, 7, 7324-7338 (2014).

https://doi.org/10.3390/ma7117324

[13] François C., Pourchet S., Boni G., Rautiainen S., Samec J., Fournier L., Robert C., Thomas C. M., Fontaine S., Gaillard Y., Placet V., Plasseraud L.: Design and synthesis of biobased epoxy thermosets from biorenewable resources. Comptes Rendus Chimie, 20, 1006-1016 (2017).

https://doi.org/10.1016/j.crci.2017.10.005

[14] Kumar S., Samal S. K., Mohanty S., Nayak S. K.: Recent development of biobased epoxy resins: A review. Polymer-Plastics Technology and Engineering, 57, 133-155 (2018). https://doi.org/10.1080/03602559.2016.1253742

[15] Liu X., Zhang J.: High-performance biobased epoxy derived from rosin. Polymer International, 59, 607-609 (2010).

https://doi.org/10.1002/pi.2781

[16] Liu X. Q., Huang W., Jiang Y. H., Zhu J., Zhang C. Z.: Preparation of a bio-based epoxy with comparable properties to those of petroleum-based counterparts. Express Polymer Letters, 6, 293-298 (2012). https://doi.org/10.3144/expresspolymlett.2012.32

[17] Jaswal S., Gaur B.: Structure-property correlation study of bio-based multifunctional vinyl ester resin in presence of methacrylated lignin model compounds. Polymer Science Series B, 57, 417-433 (2015). https://doi.org/10.1134/S1560090415050048 
[18] Hasan A. M. A., El-Saeed A., Al-Shafey H., El-Sockary M., El-Ghazawy R.: A preliminary study on liquid crystalline epoxy curatives from natural abietic acid. Egyptian Journal of Petroleum, 28, 127-136 (2019).

https://doi.org/10.1016/j.ejpe.2018.12.003

[19] Atta A. M., Mansour R., Abdou M. I., Sayed A. M.: Epoxy resins from rosin acids: Synthesis and characterization. Polymers for Advanced Technologies, 15, 514-522 (2004).

https://doi.org/10.1002/pat.507

[20] Atta A. M., Elsaeed A. M.: Preparation and evaluation of epoxy binders based on rosin as organic coating for steel. Recent Patents on Corrosion Science, 1, 132-143 (2014).

https://doi.org/10.2174/2210683911101020132

[21] El-Ghazawy R. A., El-Saeed A. M., Al-Shafey H. I., Abdul-Raheim A. R. M., El-Sockary M. A.: Rosin based epoxy coating: Synthesis, identification and characterization. European Polymer Journal, 69, 403-415 (2015). https://doi.org/10.1016/j.eurpolymj.2015.06.025

[22] Bobade S. K., Paluvai N. R., Mohanty S., Nayak S. K.: Bio-based thermosetting resins for future generation: A review. Polymer-Plastics Technology and Engineering, 55, 1863-1896 (2016).

https://doi.org/10.1080/03602559.2016.1185624

[23] Atta A. M., Mansour R., Abdou M. I., El-Sayed A. M.: Synthesis and characterization of tetra-functional epoxy resins from rosin. Journal of Polymer Research, 12, 127-138 (2005).

https://doi.org/10.1007/s10965-004-2936-x

[24] Deng L., Ha C., Sun C., Zhou B., Yu J., Shen M., Mo J.: Properties of bio-based epoxy resins from rosin with different flexible chains. Industrial and Engineering Chemistry Research, 52, 13233-13240 (2013). https://doi.org/10.1021/ie4005223

[25] Liu X., Xin W., Zhang J.: Rosin-derived imide-diacids as epoxy curing agents for enhanced performance. Bioresource Technology, 101, 2520-2524 (2010). https://doi.org/10.1016/j.biortech.2009.11.028

[26] Wang H., Liu X., Liu B., Zhang J., Xian M.: Synthesis of rosin-based flexible anhydride-type curing agents and properties of the cured epoxy. Polymer International, 58, 1435-1441 (2009).

https://doi.org/10.1002/pi.2680

[27] Wang H., Liu B., Liu X., Zhang J., Xian M.: Synthesis of biobased epoxy and curing agents using rosin and the study of cure reactions. Green Chemistry, 10, 11901196 (2008). https://doi.org/10.1039/b803295e

[28] Wazarkar K., Kathalewar M., Sabnis A.: Anticorrosive and insulating properties of cardanol based anhydride curing agent for epoxy coatings. Reactive and Functional Polymers, 122, 148-157 (2018). https://doi.org/10.1016/j.reactfunctpolym.2017.11.015

[29] Liu X., Xin W., Zhang J.: Rosin-based acid anhydrides as alternatives to petrochemical curing agents. Green Chemistry, 11, 1018-1025 (2009). https://doi.org/10.1039/b903955d

[30] Wang H., Wang H., Zhou G.: Synthesis of rosin-based imidoamine-type curing agents and curing behavior with epoxy resin. Polymer International, 60, 557-563 (2011). https://doi.org/10.1002/pi.2978

[31] Sharma P., Choudhary V., Narula A. K.: Effect of structure of aromatic imide-amines on curing behavior and thermal stability of diglycidyl ether of bisphenol-A. Journal of Applied Polymer Science, 107, 1946-1953 (2008). https://doi.org/10.1002/app.26644

[32] Grob D.: Recommended methods for the analysis of alkyd resins. Butterworth, London (1973).

[33] Division of paint, plastics and printing ink chemistry. Chemical \& Engineering News Archive, 32, 38453846 (1954). https://doi.org/10.1021/cen-v032n039.p3845

[34] Chiu Y-C., Huang C-C., Tsai H-C., Prasannan A., Toyoko I.: Effect of aromatic and aliphatic amines as curing agents in sulfone epoxy monomer curing process. Polymer Bulletin, 70, 1367-1382 (2013). https://doi.org/10.1007/s00289-013-0942-z

[35] Burkanudeen A., Ramesh P.: Novel latent epoxy curing agent for secondary insulation in electrical rotors and stators. IEEE Transactions on Dielectrics and Electrical Insulation, 19, 1791-1798 (2012). https://doi.org/10.1109/TDEI.2012.6311529

[36] Smith C. A.: Characterisation of polymers used in printed circuit board manufacture. Polymer Testing, 7, 7984 (1987). https://doi.org/10.1016/0142-9418(87)90002-X

[37] Thakkar J. R., Patel R. D., Patel R. G., Patel V. S.: Glass fiber reinforced composites of epoxy resin cured with different amines. Die Angewandte Makromolekulare Chemie, 172, 103-111(1989). https://doi.org/10.1002/apmc.1989.051720109

[38] Dharwadkar S. R., Kharkhanawala M. D., Schwenker R. P., Garn P. D.: Thermal analysis in organic materials and physical chemistry. Academic Press, New York (1969).

[39] Feldman D., Barbalata A.: Synthetic polymers: Technology, properties, applications. Chapman, London (1996).

[40] Helwig E. J., Biber H. E.: The use of the scanning electron microscope in investigating container corrosion by canned foods and beverages. Food Structure, 9, 195202 (1990). 